Portland State University

PDXScholar

Spring 6-3-2015

\title{
Use of Role and Power in Parent-Teacher Relationships: Perceptions from the Parent Perspective
}

Sonja Taylor

Portland State University

Follow this and additional works at: https://pdxscholar.library.pdx.edu/open_access_etds

Part of the Education Commons, and the Other Communication Commons Let us know how access to this document benefits you.

\section{Recommended Citation}

Taylor, Sonja, "Use of Role and Power in Parent-Teacher Relationships: Perceptions from the Parent Perspective" (2015). Dissertations and Theses. Paper 2324.

https://doi.org/10.15760/etd.2321

This Thesis is brought to you for free and open access. It has been accepted for inclusion in Dissertations and Theses by an authorized administrator of PDXScholar. Please contact us if we can make this document more accessible: pdxscholar@pdx.edu. 
Use of Role and Power in Parent-Teacher Relationships:

Perceptions from the Parent Perspective

by

Sonja Taylor

A thesis submitted in partial fulfillment of the requirements for the degree of

Master of Science

in

Sociology

Thesis Committee:

Emily Shafer, Chair

Lindsey Wilkinson

Candyce Reynolds

Portland State University

2015 
(C) 2015 Sonja Taylor 


\begin{abstract}
Studies have increasingly shown that more parent involvement leads to higher academic achievement for kids. However, studies have also shown a difference in the ability of parents to effectively further their children's interest based on social class. Middle-class parents are described as being able to activate their cultural and social capital in order to further their interests, while working-class and low-income parents have been described as frustrated and marginalized - lacking the ability to activate their capital in a way that benefits themselves and their children.

The intent of this study is to explore how parents understand their role in the parent-teacher relationship to look for evidence that social class might not be as much of a factor as previous literature suggests when it comes to activation of cultural capital. Building on a study that found some working-class parents were able to activate cultural capital through their conversations with teachers, I wanted to find out if how parents understand and perform their role would offer more insight into how cultural capital is activated. Based on the premise that how parents understand their role in conversation with teachers might be able to affect their ability to activate their cultural capital, I conducted a qualitative interview study to explore how parents of $5^{\text {th }}$ grade elementary students view their role in the parent-teacher relationship.

Results of the study show that parents gained confidence in their role through conversations with teachers and that they also gained an increased ability to collaborate and engage in partnership with their children's teachers. Confidence in role and collaboration with teachers were seen as indications of activation of cultural capital. In
\end{abstract}


this study, parents were able to activate their cultural capital by having collaborative relationships with teachers 9 out of 10 times, regardless of class background.

I draw conclusions that parents in my study developed the ability to activate cultural capital regardless of social class background. Because of this, parents' experience of their relationships with teachers might not be as dichotomous as previous research suggests. My findings suggest that frequency of communication is an important mechanism that contributes to successful parent-teacher relationships. Communication that was particularly helpful included informal conversations and email. The use of email in parent-teacher conversations in particular is an area that deserves further study. 
for

Donovan Alfred Lawrence Young

and

Liam Anton Hunter Young 


\section{Acknowledgements}

They say it takes a village to raise a child, but I think it also takes a village to support an adult. I am privileged to have a large village that continues to grow, support and encourage me in all my aspirations. Firstly, I would like to thank my committee chair - Dr. Emily Shafer - for being an endless source of inspiration, motivation and encouragement. I am grateful for the additional wisdom and support of Dr. Lindsey Wilkinson and Dr. Candyce Reynolds. I also want to thank the parents who participated in this study, without whom none of this would have been possible.

There is a long list of people from the Sociology Department for me to thank and I don't think I can do it all here. I do want to specifically thank Dr. Tina Burdsall and Dr. Matthew Carlson for important feedback and support at critical moments of my research process. Of course, none of us would be able to do what we love without the presence of Bahar Jaberi and Kris Lucht-Adams. Thank you both for always having the answer, even when we ask the same question a million times.

I have joked often about straddling cohorts and I feel extremely blessed to have connected with so many wonderful fellow scholars on my academic journey. I need to specifically thank Dylan Waite for being my constant sounding board throughout this whole process. You offered me key suggestions exactly when I needed them and opened intellectual doors I felt like I was banging my head against at precisely the right moments. I can't thank you enough for your unflagging friendship and support. Robin, Heidi and Bryan - thank you for being there until the end, in addition to all the support and friendship you offered along the way! Neil, I just don't know what I would have 
done without you - thank you for always pushing me to do my best. Whitney, Bernie, Trent, Liz and Heather - Thank you for your feedback, your insights, your commiseration, and your enthusiasm for my project.

I have amazing friends. I am humbled and grateful to have so many wonderful people in my life and for so many years. Thank you Jen, Erica and Cat for showing up for the finish line and cheering me on - we are a long way from growing up in Newport Oregon. Of course, the foundation of all my support comes from my family. Being able to present my research to an audience that included my parents and my grandmother was an amazing gift.

Lastly, but certainly not least - I want to thank my two sons, Donovan and Liam, for putting up with all of the craziness over the last few years. I am sorry to disappoint you by not leaving school because I am (as Donovan says) "too old to keep going to school" or in order to (as Liam requested) "get a job in a restaurant so I can come and visit you and eat food." I know that when you are older, you will understand. 


\section{Table of Contents}

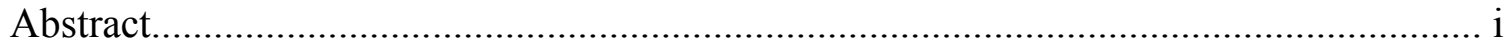

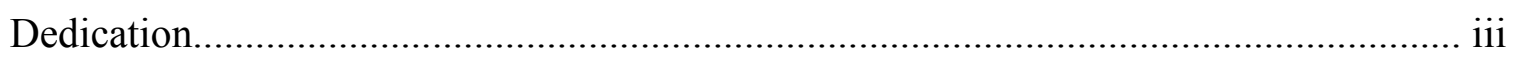

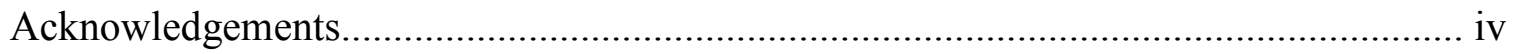

List of Tables..................................................................................................... vii

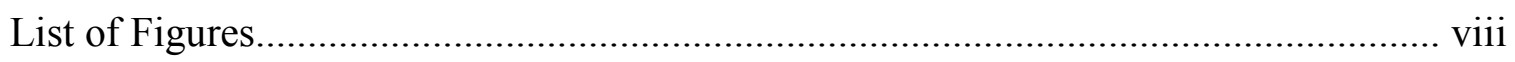

Chapter 1

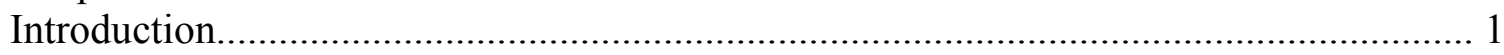

Chapter 2

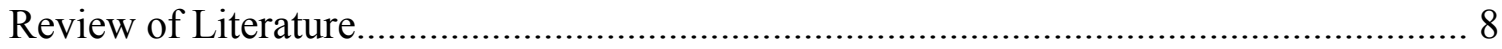

Chapter 3

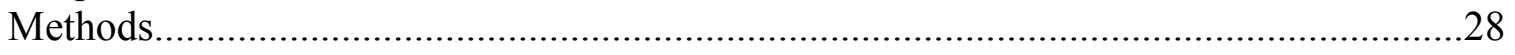

Chapter 4

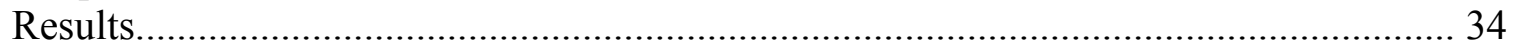

Chapter 5

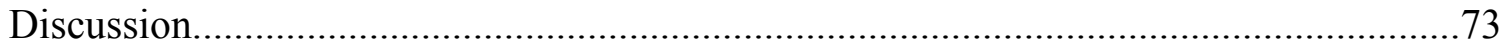

Chapter 6

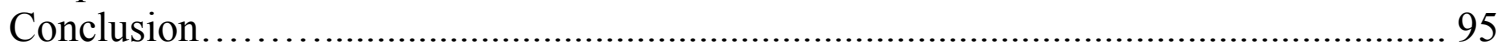

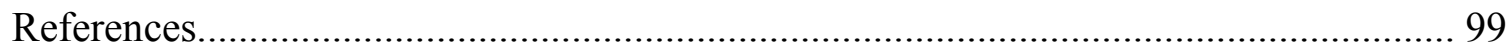

Appendix

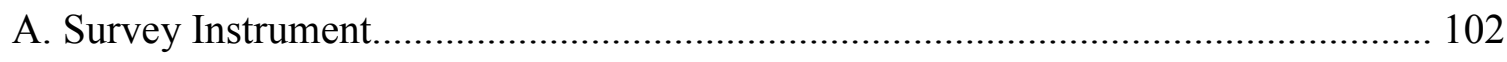


List of Tables

Table 1: Participant Demographics........................................... 37 


\section{List of Figures}

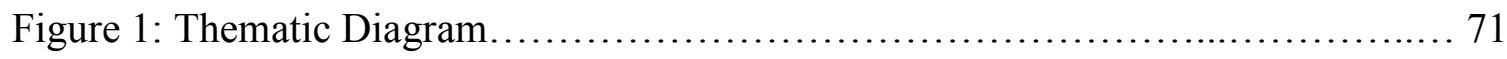




\section{Chapter 1: Introduction}

Public schools are asking for more involvement from parents, in part because research keeps expanding on the link between parent participation and better academic outcomes for children (Harris \& Goodall 2008, Lee \& Bowen 2006, Tood \& Higgins 1998, Yoder \& Lopez 2013). Implicit in the idea of parent participation in school is the concept of a home-school or parent-teacher relationship. This relationship has evolved over time (Lareau 1987) and continually shows up in the literature as being an important element of parent involvement (Day 2013, Freeman 2010, Harris \& Goodall 2008, Landeros 2011, Lareau 1987, Lee \& Bowen 2006, Reay 2004, Todd \& Higgins 1998).

Articles about parent involvement usually reference Pierre Bourdieu when talking about cultural capital and although Bourdieu also defines social capital, most of the articles about social capital and parent involvement reference James Coleman. Bourdieu

talks about cultural capital as the ability of an individual to access resources and use their knowledge, skills and language for their benefit (Bourdieu 1990). Within existing literature, Bourdieu and Coleman both talk about social capital as derived from group membership (Bourdieu 1990 and Coleman 1988). While both Bourdieu and Coleman describe social capital, most of the literature on parent involvement cite Coleman when talking about social capital and describe that capital as being housed within parent networks (Horvat et. al. 2003).

Both forms of capital are "productive, making possible the achievement of certain ends that in its absence would not be possible" (Coleman 1988). In other words, 
individuals use cultural and social capital to effect outcomes in a way that benefits them. They can either use capital they possess themselves or access capital they are connected to through memberships within a particular group. All people possess cultural and social capital however; individuals "vary in the skill with which they activate it" (Lareau and Horvat 1999, 38).

The literature on parent involvement in school uses both cultural and social capital. The discussion on cultural capital often focuses on parent comfort with and sense of trust for the institution (Lareau 2011), although it is also used in reference to parents getting positive outcomes for themselves through "activation" of cultural capital (Horvat and Lareau 1999). When the literature describes social capital it focuses more on parents getting what they want from teachers and schools (Horvat et. al. 2003). For example, Lareau, Horvat and Weininger talk about social capital and parent networks as a way to access institutional knowledge (Horvat et al. 2003). While on the other hand, Lareau talks about lack of cultural capital as a barrier to parental involvement for families with a low SES background (Lareau 2011). Within these different conversations, there are examples of the parent-teacher relationship as one aspect of parent involvement, usually this part of the conversation is focused on the parent's ability to "activate" their cultural or social capital and this can be seen in the different roles parents take on in the parent-teacher relationship.

Much of the current literature talks about the impact of social class on different roles that parents take on - for example the role of listener, advocate or instigator (Day 2013, Freeman 2010, Harris \& Goodall 2008, Landeros 2011, Posey-Maddox 2013). 
Specifically, middle-class parents are seen as entitled and able to activate their social capital while working-class and low-income parents are seen as possibly marginalized and frustrated by their interactions with teachers and schools (Lareau 1987, Lee \& Bowen 2006, Posey-Maddox 2013, Reay 2004, Todd \& Higgins 1988, Yoder \& Lopez 2013).

The different understandings that parents have of power, role and relationship play an important part in how parents operate within their conversations with teachers (Day 2013, Freeman 2010, Harris \& Goodall 2008, Landeros 2011). Because of this, the perceptions and understandings of parents - regarding their role and how they feel about their position in it - becomes an important factor in their children's academic success (Day 2013, Freeman 2010, Harris \& Goodall 2008 \& Landeros 2011). Parents who are more able to "activate" their cultural and social capital within their relationships with teachers are better equipped to help their children succeed.

Existing research on parent perceptions has focused largely on how parents perceive their ability or inability to become involved in their children's educational experiences at school and in the community (Freeman 2010, Gillies 2006, Lareau 2003, Tveit 2009, Yoder and Lopez 2013). There is little focus on how parents view their role in the parent-teacher relationship. However, some research suggests that parents can use conversations with teachers to understand how to navigate educational institutions more successfully (Freeman 2010). In effect, they might use the parent-teacher relationship to help them "activate" their capital. However, there is very little research in this area.

My research addresses this gap by investigating the perceptions parents have of their own roles and the roles of teachers in the parent-teacher relationship and how their 
confidence in that role has changed over time. Perception of roles in conversation demonstrates awareness of "micro-interactions" which have been identified in the literature as a mechanism for gaining cultural capital (Reay, 2004, 74). Thus, the "microinteractions" between parents and teachers presents an ideal place to investigate and look for signs of the activation of cultural capital.

One example of activation of cultural capital is confidence and familiarity with knowledge; skills and language that will help an individual reach outcomes that benefit them. In my research I look specifically at confidence gained as a result of "microinteractions" between parents and teachers in order to explore the possibility of cultural capital being activated within the parent-teacher relationship. To accomplish this I conducted and analyzed 10 interviews with parents of 5th grade students as a way provide some insight into viewing the parent-teacher relationship in elementary school.

Initially I was looking for ways that parents used their conversations with teachers in creating their role as parent in the interaction. I was looking at how the conversations might help parents construct their identity as a parent over time. I found two important factors in the interactions with teachers that led me to believe relationships with teachers could be a source for activation of cultural capital. One factor was confidence in their role within the parent-teacher relationship and familiarity with institutional norms. The other factor was an emphasis on collaboration or partnership with teachers as a preferred structure for parent-teacher conversations.

I believe that parent confidence in their role has to do with understanding skills and language specific to educational institution and in that way confidence partially 
demonstrates activation of cultural capital. Collaboration also suggests activation of cultural capital because in collaboration and partnership, parents seem able to use their knowledge and language skills to get outcomes that are to their benefit. One way to think about collaboration is that parent-teacher relationships contain experts in different fields - the parent is the expert in the child and the teacher is the expert in the field of education. It seems reasonable to suppose that children will benefit most when these two "experts" work together in a positive way; gaining knowledge from each other about the spheres where they have less experience.

This study was conducted in Portland, Oregon with parents who have at least one child currently enrolled as a $5^{\text {th }}$ grade student in a Portland Metro Area elementary school. I chose $5^{\text {th }}$ grade parents specifically in order to talk to individuals who had a variety of experiences with different teachers. Semi-structured interviews were conducted to delve into parent's understanding of teachers' roles and their own roles in the conversations that occur between parents and teachers throughout the school year. I asked parents to reflect on the most meaningful aspects of the conversations they had with teachers, as well as the positive and negative interactions within conversations they experienced.

Throughout the interviews, parent narratives revealed multiple important areas of communication that can be viewed as contributing factors in the confidence they feel in their role within parent-teacher conversations. One of the areas is defined as informal conversations - these take place at pick-up and drop off, but also during side conversations parents have while volunteering and informal moments connected to 
school functions such as back to school night. The other area that stood out was the proliferation of email and increasing use of email as a way that parents and teachers communicate on a regular basis. In both instances a more frequent level of interaction was associated with more confidence in their role.

This study is potentially significant for both policy and practice. Overall, this study will add to existing literature about parent participation by highlighting the relationship between parents and teachers and how parents understand that relationship and their roles within it. In addition, this study shows why more careful examination of the parent-teacher relationship is warranted. Ramifications could be particularly important for parents with low SES backgrounds because of previous literature citing the marginalization felt by low-income parents. If building a strong parent-teacher relationship in elementary school helps working-class and low-income parents activate cultural capital within educational spheres, there are broad implications for how schools might shape a more intentional approach to building those relationships.

\section{Summary of chapters}

In chapter 2 I review the literature on both guiding theory and topic. I chose to focus first on theory because it frames my results and discussion, but it also threads through the existing literature on parent involvement in schools. Chapter 3 is focused on my research methodology including data collection and analysis. My results are presented in chapter 4 broken into different themes that emerged during analysis. In chapter $5 \mathrm{I}$ discuss my results in combination with relevant literature, situating my findings firmly in 
my understanding of Bourdieu's concept of cultural capital. Chapter 6 contains my conclusions and suggestions for future research. 


\section{Chapter 2: Review of the Literature}

In this chapter I examine the existing literature surrounding parents, participation and the roles cultural and social capital play in the discussion. First, I will engage in a discussion of my guiding theoretical framework. This is important as my study is closely tied to theory, since it is qualitative with limitations in terms of generalizability and representativeness. Second, I will turn to the literature surrounding my specific topic and begin with a brief history of the parent-teacher relationship, a relationship housed within the home-school connection. Third, I will discuss how social class has been used to frame the discussion of parent involvement in elementary school because it is important contextually - because that is how cultural and social capital have traditionally been understood when it comes to the parent-teacher relationship. In addition, I will discuss the importance of role and power dynamics and what part those concepts will play in the discussion. I will conclude with specific reasons the existing literature invites my particular study.

\section{Theoretical Framework}

Much of the previous research focuses on the cultural and social capital enjoyed by middle class parents and how they activate their capital in order to further the interest of their children, while working-class and low-income parents lack the ability to activate their cultural and social capital (Lareau and Horvat 1999, Horvat et al. 2003, PoseyMaddox 2012, Reay 1999). It is important to have a clear understanding of the definitions 
of different forms of capital because there are areas where they overlap as well as places of transition where one form of capital is converted into a different form of capital. With that in mind I will expand a little on the way different forms of capital have been defined.

Economic capital is the easiest to quantify as it is tied to material wealth and is “immediately and directly convertible into money" (Bourdieu 2011, 82). Economic capital has also been referred to as the "most rationalized form of capital" because of the ability to translate it monetarily (Geleta 2014, 115). Basically, economic capital describes money and other tangible assets that can be easily transferred and quantified. Cultural and social capital may be converted into economic capital, but the connection to monetary gain is less explicit and requires transformation in various ways (Bourdieu 2011, 82).

Bourdieu defined cultural capital in three parts - embodied, objectified and institutionalized (Bourdieu 2011, 82). Embodied cultural capital refers to "long lasting dispositions of the mind and body" (Bourdieu 2011, 82). Objectified cultural capital refers to cultural goods and is bound up with embodied cultural capital in that one must possess the embodied for of capital in order to correctly use the tools of objectified cultural capital (Bourdieu 2011, 85). Institutionalized cultural capital refers to institutionalized recognition of cultural capital, usually by degree or "academic qualification" (Bourdieu 2011, 86).

Cultural capital has also been defined as an understanding of "culturally-valued competencies and Knowledge" (Geleta 2014, 116). More specifically and for the purposes of application to this study, cultural capital has been defined as "familiarity with the dominant culture in the society and especially the ability to use educated language" 
(Reay 2004, 74). Previous literature has focused on language acquisition - meaning knowledge of the lexicon surrounding high status cultural participation - as mastery of this form of capital (Reay 2004, 74).

Bourdieu defines social capital as a kind of capital that is linked to "membership in a group" (Bourdieu 2011, 86). He goes on to say that the social capital possessed by a "given agent" depends on the "size of network connections he can effectively mobilize and the volume of capital (economic, cultural or symbolic) possessed in his own right by each of those to whom he is connected" (Bourdieu 2011, 86). Thus, cultural capital could be viewed as possessed by the individual absolutely, while social capital requires a connected network in order to access it.

Coleman has also developed a framework for understanding social capital and his work has been cited often in research on parent networks. Parental networks have been one of "the most frequently invoked kinds of social capital" (Horvat et al. 2003, 320). Horvat et al. found that there are "important class-specific differences in the architecture of parental networks and, associated with this, in parents' capacity to effectively intervene in school matters" (Horvat et al. 2003, 320). They further argue that "network ties connecting parents of school peers is primarily a middle-class phenomenon" while working class and poor families depend more on their "kinship lines" (Horvat et al. 2003, $320)$.

Horvat et al. conclude that "in the educational context, social capital may be just as likely to function as a mechanism that facilitates the intergenerational transmission of advantage as one that ameliorates its effects" (Horvat et al. 2003, 321). While working- 
class and low-income parents do have access to social networks, "the social networks accessible by working-class and poor families are less valuable than those of middle-class families for negotiating the institutional environment formed by the school" (Horvat et al 2003, 323).

Although the social networks of parents from working-class and low-income backgrounds might be less helpful for navigating educational institutions, their relationships with teachers may provide a direct access to the institutional cultural capital held by teachers. In other words, when looking at macro forms of parental support there is a divide between the social capital that middle-class parents can access and the social capital available to working-class and poor parents. However, on a micro level all parents may have access to the teachers in elementary school and those teachers can be a valuable resource.

When looking at individuals, Lareau and Horvat note that it is important to differentiate between "the possession and activation of capital" (Lareau and Horvat 1999, 44). They further suggest dominant groups can gain an advantage by constructing a relationship with schools that includes more "comfort and trust" (Lareau and Horvat 1999, 44). The suggestion is that this is easier for middle-class parents, but some authors suggest that parents from other class backgrounds can gain benefits and knowledge of how to activate capital over time (Freeman 2010). It seems as if there is a gap in our understanding of how working-class and low-income parents might activate their cultural capital in beneficial ways. 
I would like to build on the idea of the parent-teacher relationship as a source of capital available to a wider variety of parents by looking at the way parents understand their role in parent-teacher conversations and how they position themselves within it. Melissa Freeman does this by adding the concept of a "discursive practice of involvement" and positioning theory in parent-teacher conversations. Freeman suggests, "positioning analysis of personal narratives is one way of gaining a better understanding of how class is played out in everyday parental involvement activities rather than a determinant of those activities" (Freeman 2010, 182). This concept brings a sense of agency to the role that working-class parents play, different than the agency of middleclass parents. Freeman describes how working-class parents "fostered a discourse that can best be described as counter-hegemonic in that it resisted the tendency of school personnel to treat them as lower class" (Freeman 2010, 184).

When Freeman talks about discursive positioning she is really describing a method for parents to activate their cultural capital. Freeman is describing this process when she says "'”for the working-class parents, therefore, the dialog itself served as a discursive resource that contributed to their developing knowledge about teaching and learning, school opportunities, and values" (Freeman 2010, 194). These resources are actually the cultural capital that has been documented as an advantage for middle-class parents.

As Freeman suggests, the parent-teacher relationship is a resource that could potentially be available to all parents as a way of accessing the cultural capital that teachers possess, through conversation with teachers in elementary school in successive 
years. Freeman's article focuses on working-class parents and uses the idea of "discursive positioning" that is intentionally employed by parents in a particular school. Positioning theory itself is a psychological theory having to do with the creation of identity in dialogue with another person over time. Essentially the idea is that parents create an understanding of their role and how to better position themselves and their children through conversations with teachers over time.

Freeman's study reports on findings from interviews with parents of different SES backgrounds and then focuses on interviews with four white, working class parents who actively sought out ways to "build collaborative relationships with teachers and administrators as equal, respected partners in the education of their children" (Freeman 2010, 182). Freeman goes on to say that working-class parents in her study intentionally situate themselves in a particular role by "positioning themselves in relationship to school personnel as legitimate educational partners, and by requiring that partnership be built on open and frequent communication between home and school" (Freeman 2010, 185). However, Freeman limits the benefits of discursive positioning to parents from her study with working-class backgrounds and excludes low-income parents from the process by giving them a passive role where they sit expressing the "desire to be invited" while lacking the power to engage in the same process (Freeman 2010, 189).

The concept of discursive positioning has been used in understanding how beginning teachers develop their professional identity. One study in particular documents this process in the form of a mentoring partnership where beginning teachers are assigned a "teacher-mentor" from whom they "learn to expect less a step-by-step behavioral 
guidance and more a partnership in a dialogical approach to building practical and reflective knowledge, as well as in reaching what could constitute a personal touch" (Mitescu 2014, 31). Mitescu touches briefly on the idea of mentoring and dialogue as an avenue for gaining understanding of process and is similar to the observations made by Freeman.

Rom Harre theoretically outlines the process of creating an identity through dialogue with another individual in the article "The Discursive Production of Selves." Harre begins with a description of the way we understand self or selves. Initially Harre describes Self 1 and Self 2 with self 1 being the internal understanding of the individual and self 2 being the "selves that are publicly displayed by the one embodied" or what we might project to others and which might vary depending on company (Harre 1991, 52). Relevant to my inquiry about discursive positioning of parents, Harre describes an identity or self, which emerges "in the discursive practices of interpersonal and jointly forged conversations" (Harre 1991, 53). The "jointly forged conversations" for this study are the conversations between parents and teachers in elementary school.

In this section I have provided an overview of the literature specifically looking at the guiding theory I will use as a framework for my study. I have talked about the different forms of cultural and social capital as described by Bourdieu and I have shown how some of those concepts have been used in the literature on parent involvement in schools. I have described discursive positioning and positioning theory as a possible mechanism for activating cultural capital and how these micro-level conversations can 
contribute to the resource parents can access. In the next section I will look more at the literature that describes parent involvement more broadly.

\section{History of the Parent-Teacher Relationship}

The emphasis on parent involvement in school is linked to research that shows parent participation linked to better academic outcomes for kids. The call for increased parental participation draws the relationship between home and school out for examination. Currently it is possible, even likely, for parents to be directly involved in the curricular process - sometimes acting as teachers themselves. However, this level of involvement is a relatively recent development. The home-school relationship has evolved over time and in a nonlinear fashion (Lareau 1987, 74).

Lareau identifies three major stages historical of macro-level family-school interaction within the United States. Even though she describes the evolution of this relationship as non-linear, the overall trend seems to move from teacher as family to parent as teacher. The first stage of family-school relationship could be seen as "teacher as family" because in rural areas the teacher actually depended on families for room and board (Lareau 1987, 74). In the second stage, which Lareau describes as an era "marked by the rise of mass schooling," parents were involved with activities but not “fundamentally involved in their children's cognitive development” (Lareau 1987, 74). The third stage, continuing to present day, parents are actively involved in supporting school curriculum at home as well as developing a "growing role in monitoring their 
children's educational development ... and have moved into the classroom as volunteers" (Lareau 1987, 74).

In fact, one author makes the claim that "we have now reached a point at the beginning of the $21^{\text {st }}$ century when parental involvement is no longer optional as parents are increasingly seen to be co-educators alongside their children's teachers" (Reay 2004, 76). Reay connects the influence of social class to participation when she says that mothers' "effectiveness in dealing with teachers and such (class) differences are powerfully rooted in cultural capital” (Reay 2004, 77).

Multiple studies have linked parental involvement with positive academic outcomes in school (Billingham \& Kimelberg 2013, Harris \& Goodall 2008, Lee \& Bowen 2006, Oseguera et al 2011, Taylor et al. 1995 \& Todd \& Higgins 1998). Within this research on parent involvement, many studies also cite the importance of the parentteacher relationship as one form of participation (Day 2013, Freeman 2013, Harris \& Goodall 2008), Landeros 2011, Lareau 1987, Lee \& Bowen 2006, Todd \& Higgins 1998 \& Reay 2004). When parents and teachers work together, they create a shared understanding of the academic requirements so that what happens at school can be reinforced at home. In fact, Landeros notes "the parent-teacher partnership is considered one of the most important factors for a child's educational success" (Landeros 2011, 247). It is this dyadic relationship, and the potential for it to contribute to the identity of parents in a way that increases their cultural capital, that is the focus of this particular study. 


\section{Social Class and Participation}

Research indicates that parent participation in school looks different based on the social class of parents and further, that the participation exhibited by middle-class parents is valued more highly. In this section I will look at the different ways the impact of social class has been expressed within the literature on parent-teacher relationships. I will begin with an exploration of the literature around how parent participation is defined and valued. Next I will look at how cultural capital has been described as a resource that divides parent experiences of dialogue with teachers. Finally, I will end this section with research that suggests conversations with teachers are a resource for working-class parents to develop cultural capital.

The literature points to a difference in the way parent participation is both perceived and valued, based on social class. For example Gillies states that the "ideal of parental involvement shaping contemporary education policy is firmly grounded in a middle-class visibility and engagement with social structures" (Gillies 2006, 289). Because middle-class parents can contribute more financially, their participation is highly valued and sought after, while working-class and low-income parents tend to participate more through helping kids with their homework, participating in conferences and occasionally volunteering in the classroom. By emphasizing the contribution of middleclass parents, the "valuable contribution made by working class mothers remains hidden" (Gillies 2006, 289).

This difference in parent participation leads to increased academic advantage for children of middle class parents (Landeros 2011, Lareau 1987, Lee \& Bowen 2006, 
Posey-Maddox 2013, Todd \& Higgins 1998 \& Yoder \& Lopez 2013) and it contributes to the marginalization of lower income parents (Gillies 2006, Lee \& Bowen 2006, PoseyMaddox 2013, Reay 2004, Todd \& Higgins 1998 \& Yoder \& Lopez 2013). Beyond general categories of entitlement or marginalization, research more specifically addresses a negative view of low-income and working-class parents based on the types of participation they engage in (Lee \& Bowen 2006, 198).

Lee and Bowen (2006) specifically articulate the forms of participation referred to in the literature on parent involvement. Participation is first broken down into the categories of school and home, and then each of those is further broken down into subcategories. The school categories of participation include parent/teacher conferences, volunteering at school, volunteering in the classroom and attending school events (Lee \& Bowen 2006, 202). The home categories of participation include discussing educational topics with children, help with homework and managing children's time so they get adequate time for homework (Lee \& Bowen 2006, 202). Additional categories of "informal conversations" at school and phone conversations (possibly email in today's context) have also been described and both of these fall under the purview of parent/teacher relationship (Tveit 2009, 289).

There has been some discussion in the literature about the ways parents communicate with teachers and whether or not that helps or hinders academic achievement. Research citing Bourdieu's concept of habitus claims that educational institutions favor middle-class parents because their habitus more closely matches the habitus of the institution (Landeros 2011, Lareau 1987, Lee \& Bowen 2006, Posey- 
Maddox 2013, Todd \& Higgins 1998 \& Yoder \& Lopez 2013). Annette Lareau is frequently cited in the literature surrounding class, parenting and elementary education. She argues, "interactions with representatives of major social institutions" including schools “appeared significantly shaped by class” (Lareau 2002, 765).

Lareau gives examples of working class and low-income families' distrust for authority in educational institutions (Lareau 2002, 765). In one story she describes a mother on public assistance, "outraged that the school personnel had allowed her daughter to come home from school one winter day without her coat" and further, "noted that if she had allowed that to happen, "the school" would have reported her to Child Protective Services for child abuse" (Lareau 2002, 765). In another story, a working-class mother complained that she felt obligated to take her daughter to the doctor, "even when she knew nothing was wrong" because her daughter had seen the school nurse (Lareau $2002,765)$.

In addition, research suggests that teachers might feel more comfortable with middle-class parents whose habitus more closely resembles their own and that of the institution. They may show this preference for dealing with middle-class parents by a process of "infantilism." This process is revealed "in interactions between teachers and working-class mothers" (Reay 1999, 165). Reay describes how teachers "redefined" parents as "pupils in need of instruction alongside their own children" (Reay 1999, 165). Parents interviewed by Reay expressed negative feelings because of the different treatment they received. One mother said that when she went to school to discuss her 
daughter's lack of progress in reading "the Head teacher made her feel 'like a naughty school girl” (Reay 1999, 166).

On the other hand, some research suggests that the link between social class and parent interaction with educational institutions is not as strong as Lareau and Reay have suggested. In fact, Lareau herself suggests that there are exceptions when she says "The social reproduction model has implied that the passing of privilege of family to child is relatively automatic. It is not" (Lareau and Horvat 1999, 48). In support of that, one study claims that parental involvement is tied to student achievement but argues that the degree to which parents adopt a particular strategy is not dependent on social class (Henderson 2013, 551).

Further, Freeman's study utilizing positioning theory describes the parent-teacher relationship as a place where working class parents can "fight against stereotypes" and "build cultural and social capital through dialog and deliberation" (Freeman 2010, 181). Freeman's observations about the parent-teacher relationship came from information gathered as part of a larger study and centered on interviews with four working class parents within the school system in the United Kingdom. Freeman explains that the "cultural space where parents and schools intersect can be construed as a discursive practice that displays certain structures, histories, and norms that exclude some people, activities, and ideals, while advancing others" (Freeman 2010, 181). Within that cultural space, Freeman looks at the communication between parents and teachers as an example of a "relational discourse" through which social class is mediated (Freeman 2010, 181). From interviews conducted as part of a larger study, she looks at the way four working 
class parents "resisted the tendency of school personnel to treat them as lower class" (Freeman 2010, 184). Freeman's findings suggest that parents “actively resist stereotypes" and deliberately position themselves as "present in the lives of their children" by "continuously intervening on their behalf" and that parents see a positive return for this involvement (Freeman 2010, 187).

While Freeman concludes that working-class parents could gain cultural capital through their conversations with teachers, she continues to emphasize that it is a battle for those parents. When working-class parents sought to intervene on behalf of their children “just being a parent wasn't enough for their perspectives to be listened to or taken seriously by teachers" (Freeman 2010, 189). In addition, she does not include lowincome parents in this battle to go against stereotypes. There is clearly a strong class division around who can benefit from the shared dialogue with teachers when she says "middle-class parents took this membership for granted and lower-class parents expressed a desire to be invited, the working-class parents saw it as their responsibility to make sure they were so positioned" (Freeman 2010, 189).

While Reay talks about the micro-interaction between parents and teachers as a place where cultural capital is manifested, she emphasizes the disadvantages parents from working-class and poor backgrounds face as a result of not having the cultural capital of middle-class parents (Reay 1999, 166). She describes cultural and social capital as qualities middle-class parents have and which working-class and low-income parents lack. As a result, she reinforces previous research around parent involvement, which marginalizes parents from lower SES backgrounds. 
In contrast, Freeman suggests that working class parents might intentionally position themselves in their conversations with teachers. She notes, "working-class parents placed the most emphasis on the relationship between their actions and their children's educational success" (Freeman 2010, 190). She draws on parental narratives to explain that "the awareness they have built from experience about the need to fight against discriminatory practices has also fostered a need to build educational know-how of parental rights and responsibilities and school practices and policies" (Freeman 2010, 191). Even with the opportunities Freeman describes, she continues to see a divide between how middle-class, working-class and low-income parents are treated and how they perceive the parent-teacher relationship. For both Reay and Freeman there is still a visible power dynamic that divides the experience of parents and it is mediated by social class.

In this section I have looked at the different ways that parent participation has been described and valued. I have shown how the concept of cultural capital is seen as a resource possessed by middle-class parents and that working-class and low-income parents have perceived a barrier created by their lack of cultural capital. In contrast, I have also shown that some research points to the possibility of working-class parents using their conversations with teachers as a way to activate cultural capital. One way that the literature describes parent perception of role is through looking at the way parents perceive the balance of power to be distributed. In the next section I will focus more closely on the concepts of role and power within the parent-teacher relationship. 
Importance of Role and Power

In this section I look more explicitly at the way parents view their role and how power is distributed in the parent-teacher relationship. First, I will look at literature that describes the parent-teacher relationship as a dynamic where power is unequally distributed in favor of the teacher. I will then turn to research, which suggests a model for viewing the relationship in a more collaborative manner. Finally I will discuss some of the research directed at how some parents gain power through developing or activating cultural or social capital.

Todd and Higgins bring the concept of power to the table when they suggest that "the partnership between parents and professionals involved in the education of the parents' child or children can never be an equal one" (Todd and Higgins 1998, 228). The authors expand on this by explaining that parents and professionals occupy different positions in relation to children and that the parent has a "much greater stake in the partnership than the professional" (Todd and Higgins 1998, 228). Furthermore, Todd and Higgins make the connection between power, social construction and role when they state "despite greater commitment claimed for parents, the social construction of the parents' role renders them with less power in their dealings with teachers" (Todd and Higgins 1998, 229).

In 2003, Sara Lawrence-Lightfoot published a book entitled "The Essential Conversation: What parents and teachers can learn from each other." Lawrence-Lightfoot discusses the parent-teacher relationship mainly through the perspective of "ten teachers - all female" (Lawrence-Lightfoot 2003, xxvi). Her focus is entirely centered on the 
formal conversation of the parent-teacher conference and of this Lawrence-Lightfoot states that these conversations are "shaped by their own autobiographical stories and by the broader cultural and historical narratives that inform their identities, their values, and their sense of place in the world" (Lawrence-Lightfoot 2003, 3).

Researchers who have looked at the reproduction of cultural capital from a micro perspective, look at the ways in which social class informs parenting style and how that plays out within the public school system. In contrast, Lawrence-Lightfoot examines close up the relationship between parents and teachers and how the "tiny drama of parentteacher conferences is an expression of a larger cultural narrative" (Lawrence-Lightfoot 2003, xxviii). In her book Lawrence-Lightfoot describes the parent-teacher relationship as historically antagonistic describing an instructor she had who referred to parents and teachers as "natural enemies" (Lawrence-Lightfoot 2003, 43). Her instructor further explained that he wanted to "convey the inevitable tensions between parents and teachers shaped by the different roles and functions they play in the lives of children" (LawrenceLightfoot 2003, 43).

Some authors have looked at parent networks as a source of developing social capital. The advantages of such networks are explored in an article on schools and parent networks where parent networks are described as a "central dimension of social capital" (Horvat et al. 2003, 319). Social networks and the social capital they provide have been seen primarily as a resource for middle-class parents while "working-class and poor parents inevitably responded" to situations that had to do with conflict between their children and school "in a purely individualized fashion" (Horvat et al. 2003, 331). 
Social capital can only be accessed by being part of a group - for example a network of middle-class parents who all have varying levels of individual embodied cultural capital (Bourdieu 2011, 86). Even though cultural and social capital are different, they do interact in the balance of power within the parent-teacher relationship because parents might feel more confident in their ability to activate their capital in beneficial ways if they understand that more resources are available to them. Parents who are members of a parent social network have access to the cultural capital of all the parents within the group. However, within the micro-interactions of parent-teacher relationships, all parents might have access to individual teachers who are experts in their field and possess direct access to institutional cultural capital that can be helpful for parents. It is possible that over the elementary school years, parents build a support network of teacher relationships and that this model contributes greatly to their confidence in their role as parent.

Although there are many findings that mention the importance of parent-teacher relationships, most research in the United States treats cultural capital as something fixed that parents either have or do not have and they fail to fully develop an investigation into how it may change. Further, while Freeman's article is compelling because she is showing that cultural capital might be gained in dialogue, it still emphasizes that there are barriers felt by working-class and low-income parents when dealing with their children's teachers.

The available literature still lacks research on how typical American parents from different class backgrounds can develop their ability to activate cultural capital in 
dialogue with teachers, as well as a more specific understanding of the mechanisms involved in that process. My study addresses this gap by focusing on the kinds of conversations parents have with teachers and how they feel about the way they interact in those conversations. I look specifically at how their confidence in their role is influenced by the conversations they are having as a way of demonstrating one element of cultural capital - familiarity and confidence with language and skills that help an individual achieve beneficial outcomes. I also look at attitudes the parents have regarding collaboration and partnership with the idea that partnership and collaboration suggest shared goals. These shared goals can be seen as evidence that parents are able to achieve beneficial outcomes for themselves and their children. I build on the research done by Freeman and suggest further that the conversation with teachers is also a mechanism by which low-income parents can activate cultural capital.

In sum, existing literature looks at the importance of cultural and social capital to the discussion of parent involvement in elementary school. Cultural and social capital are important because when parents activate these different forms of capital, they are able to achieve outcomes in their relationships with teachers that work to their benefit. Historically the conversation has largely focused on the difference in ability to activate cultural and social capital based on social class. Research on parent networks continues to dichotomize this social capital of parents based on class. However, some authors suggest that perhaps social class is not such an over-arching barrier to activation of cultural capital. 
In order to explore how some parents might activate their cultural capital regardless of class background, I needed to understand more fully how they perceive their own role and the role of the teacher within the parent-teacher relationship. By looking at how they perceived their role, I could learn more about how they understood the relationship and power dynamics. Further, I could look at how they saw themselves working with teachers and how much confidence they had in their ability to fulfill their perceived role. With all this in mind, I asked the following two research questions:

"How do $5^{\text {th }}$ grade parents in the Portland Metro area understand their role in the parent-teacher relationship?"

and

"How do 5th grade parents in the Portland Metro area understand the role of the teacher in the parent-teacher relationship?"

These main research questions informed a broader question: "Can the parentteacher relationship be a place where cultural capital is activated, regardless of social class?" 


\section{Chapter 3: Methodology}

In this chapter I will discuss my research design and methodology. I will describe the methods I used to collect my data, and why I made specific decisions about the overall design. I will talk about the process involved in conducting my interviews and then go through the various stages of my analysis. The conclusion of this chapter will set the stage for delving into my results in chapter four.

\section{Data Collection}

I conducted semi-structured qualitative interviews with ten parents of 5 th graders in the Portland Metro Area. A benefit of interviewing $5^{\text {th }}$ grade parents is that I was able to ask them to reflect on their experiences with teachers over time and allow for individual differences in experience and understanding. My intent was to explore the way that parents might have used the conversations with teachers to understand their own role in their children's education. A qualitative study provided me with an avenue of investigation that allowed the subjective understandings of parents to be expressed. I conducted the study in the metropolitan area surrounding Portland, OR because of close proximity to PSU. In addition, the area provided me with easy access to a willing population through known contacts within the school system.

The participants were all parents of at least one child currently enrolled as a 5 th grade student in elementary school within the public schools in the Portland Metro Area. 
This was the only factor required for participation and allowed me to compare the experiences of parents who had all matriculated through the school system with their children for the same amount of time. Interviewing parents of 5th graders also ensured that the parents I interviewed had all had a variety of experiences so that I could look more carefully at how experience factored into their understanding of their role. Since much of the literature focuses on the effect of social class, I did collect demographic information that allowed me to place participants in socio-economic categories as described by Annette Lareau in Unequal Childhoods.

Lareau defines middle-class as families where at least one parent "is employed in a position that either entails substantial managerial authority or centrally draws upon highly complex educationally certified skills" (Lareau 2011, 365). Working class- is defined as households where neither parent has middle-class employment and "at least one parent is employed in a position with little or no managerial authority" and where no college level skills are required (Lareau 2011,365). Originally Lareau had only these two categories, but while conducting her study she found it necessary to designate a third category "families that are traditionally excluded in social class groupings" (Lareau 2011, 347). This group she defined as low-income or poor families and they include families where parents receive some kind of public assistance and where employment is sporadic or not continuous (Lareau 2011,365). I categorized the parents in my study according to these categories in order to see if their experience of the parent-teacher relationship matched the class differentiated versions found in the literature. Even though I can't make broad claims about social class based on this study, I can make claims about the parents I interviewed and my findings can be used to justify further study. 
After obtaining approval from PSU research and strategic partnerships, I was able to begin my interviews. All participants for this study were recruited through known contacts and snowball sampling. I also made flyers and distributed them to contacts when I interviewed them so that they would have easy access to contact information. Flyers requested that possible participants contact me through email or through phone.

Participants therefore were all contacted through a combination of known contacts, snowball sampling and referrals. I started with known contacts at a school my son used to, but no longer attends. My previous time in the school allowed me some familiarity with possible participants who I reasoned might be more willing to participate because they at least recognized me from being around the school. I also chose the parents at this school as a starting point because I know that it contains students from diverse class backgrounds and I thought it would be likely that I might get parents from all three socioeconomic groups. My knowledge of an initial point of contact for parents did help me gain access to parents willing to participate, but it also presented some limitations that I will discuss later.

Ten parents expressed interest and agreed to an interview. This number of participants is consistent with previous research into parent participation where many qualitative studies involve 8-12 participants (Yoder and Lopez 2013, Freeman 2010). In addition, this number did see saturation. By interview seven I started to get information that was similar to previous interviews.

The participants set up interviews with me at a location and time that was convenient for them, typically the interviews took place in the participants' homes 
although two were conducted in a conference room available to me on campus and one took place at a café. Interviews lasted 45 minutes to an hour and were digitally recorded. Since all participants were familiar with me through attendance at school, those who invited me to their homes felt comfortable doing so. Because of this base level of trust and because the subject of my research is really about understanding parent perspectives, I did not feel safety was an issue. All participants had the option of coming to campus if they desired and most preferred the convenience of me coming to them.

Analysis

I constructed an interview guide as well as a brief demographic survey that I gave to participants when the interview had been completed. All participants were told that the survey was optional and all chose to fill it out. During the interviews I followed the question list I created, but sometimes participants covered the relevant information in the process of answering a different question. I told all parents that all information was confidential and that no information that could specifically be tied to them would be part of my finished project. Based on the demographic data I collected and referencing Lareau's guidelines for designating social class, I determined that five of the parents were middle-class, three of the parents were working-class and two of the parents were in the category of low-income or poor.

After the first interview I added a clarifying question that directly related to parent confidence in their role. I did this by adding to the question I already had about if and how their conversations had changed over the years. I followed that with a question about 
if they felt the conversations they had with teachers had helped them develop confidence in their role within parent-teacher conversations. If teacher interaction/conversations help parents feel confident in their role; that could be evidence of parents using teachers to activate cultural capital.

All interviews were stored on a password-protected device and were transcribed by me personally. Some of the parents mentioned spouses or children by name and I removed these in the course of transcription as part of the process of protecting confidentiality. After transcription was completed I printed out hard copies for initial coding and reflection. Coding is the "first step in moving beyond concrete statements in the data, to make analytic interpretations" (Charmaz 2006, 43). Following the guidelines outlined by Cathy Charmaz in Grounded Theory, I initially conducted line-by-line coding on the hard copies of my transcripts. This initial coding began the process of analysis, a "way of sorting data to make meaning" (Chramaz 2006, 45).

When finished with initial coding I had a list of codes from my research that I could add to the codes I had already developed from the themes I found in existing literature. I added these codes together and entered them into a project file in Dedoose - a web based program for qualitative analysis. In Dedoose I applied more focused coding and selected excerpts from the interviews that tied directly to narratives of the parents I interviewed. This focused coding helps "synthesize \& explain larger segments of data" (Charmaz 2006, 57).

After coding all the interviews I went back and simplified and condensed codes where necessary and ended with a codebook that provides a coherent and relevant 
representation of the important thematic concepts. During this process I created memos where stories seemed to emerge and attached them to specific themes. I then used the Dedoose software to further analyze excerpts, looking for common themes across the interviews.

After my initial coding and focused coding, I went through and copied and pasted responses based on themes that emerged from my coding process. In this way I took the thematic coding process I had developed and transitioned into theoretical coding. Theoretical coding involves finding "relationships between categories"(Charmaz 2006, 63). At this stage I began to understand ways that the stories given to me by the parents I interviewed might connect to the theory surrounding social and cultural capital evident in existing literature.

In this chapter I have presented the particulars of my research design and methodology. I have explained why I chose to conduct a qualitative interview study and specifically how I determined socio-economic categories for my participants, based on a combination of their demographic information and the guidelines set for by Annette Lareau in her research on parenting and social class. I have described the process of my analysis and discussed how coding my data began to build connections between my findings and relevant literature. In the next chapter I will discuss my results. 


\section{Chapter 4: Results}

In this chapter I will go over the data I collected from the parents who participated in this study. This chapter is broken into two sections. In the first section, I will describe their answers to the brief demographic survey as a way to create a picture of what the participants looked like and some of their contextual orientation. In the second section I will give an overview of their responses. I will go over my research questions again and how parents answered my questions and I will discuss how some of themes that emerge suggest activation of cultural capital.

\section{Participants}

I interviewed seven mothers and three fathers who were parents of 5 th grade students in the Portland Metro Area. I chose $5^{\text {th }}$ grade parents because I reasoned that they would have the maximum amount of elementary school experience with various teachers. Therefore, I felt they could reflect on the ways their role and their confidence within their role might have changed over time as a result of their interaction with teachers.

The demographic information provided by my participants is displayed in Table 1. I gave pseudonyms to all the parents to protect their anonymity. In order to choose names I Google searched the most common names and assigned them by the 
chronological order of the interviews. None of the names I chose corresponded to the actual names of any participants.

There was a wide spectrum of ages within the parents who participated - with the youngest parent being 31 and the oldest being 50 . There was also a broad range of personal education experience. Two of the parents had high school diplomas but no college (1 mother, 1 father). Three of the mothers had some college and three had bachelor's degrees. Two of the parents had advanced degrees and both of those were fathers.

Five parents lived in homes with an annual income of $60 \mathrm{~K}$ or higher. All five of these parents were married. This group included the two fathers who hold advanced degrees and two mothers with bachelors. The other mother listed "some college" for education. Two of these parents lived in single earner households. Three of the parents lived in homes with an annual income of less than $30 \mathrm{~K}$. Of those mothers, one was single, one separated and one married. Two of them listed some college and one listed high school diploma under education. Two parents fell in the middle ranges between 30$60 \mathrm{~K}$ and had variable income. This group included a married father and a single mother. The father listed high school and the mother listed bachelor of fine arts under education.

Nine of the parents listed described their 5th grader as their oldest or only child. One parent listed her child as the youngest and only child still at home. In the interviews the parent whose 5th grader was the youngest felt the most prepared when reflecting on her interactions with teachers over the years. She also described herself as coming from a low-income background with limited college education and a history of public assistance. 
Looking at the basic demographics provided by the parents shows both a homogenous sample and one that contains a relatively high amount of diversity. The homogeneity comes from the fact that all my parents were white and parents of $5^{\text {th }}$ graders in the Portland Metro Area. However, there was variety in the age, income, marital status, education and number of children within the household (See Table 1 on the next page). 
Participant Demographics

\begin{tabular}{|c|c|c|c|c|c|c|c|c|}
\hline $\begin{array}{l}\text { Participant } \\
\text { (alias) }\end{array}$ & Age & Gender & $\begin{array}{l}\text { Marital } \\
\text { Status }\end{array}$ & Ed & Occupation & $\begin{array}{l}\text { Annual } \\
\text { Income }\end{array}$ & $\begin{array}{l}\text { \# of } \\
\text { Kids }\end{array}$ & $\begin{array}{l}\text { Birth } \\
\text { order of } \\
5^{\text {th }} \text { grader }\end{array}$ \\
\hline $\begin{array}{l}1^{* *} \\
\text { (Mary) }\end{array}$ & 48 & Female & Separated & $\begin{array}{l}\text { Business } \\
\text { college }\end{array}$ & $\begin{array}{l}\text { Customer } \\
\text { Service Rep }\end{array}$ & $<30 \mathrm{~K}$ & 3 & Oldest \\
\hline $\begin{array}{l}2^{*} \\
\text { (James) }\end{array}$ & 40 & Male & Married & Master's & $\begin{array}{l}\text { Product } \\
\text { Manager (tele- } \\
\text { communications } \\
\text { company) }\end{array}$ & $>60 \mathrm{~K}$ & 2 & Oldest \\
\hline $\begin{array}{l}3^{*} \\
\text { (Patricia) }\end{array}$ & 42 & Female & Single & BFA & $\begin{array}{l}\text { Real Estate } \\
\text { Broker }\end{array}$ & $30-59 \mathrm{~K}$ & 1 & Only \\
\hline $\begin{array}{l}4^{*} \\
\text { (Linda) }\end{array}$ & 36 & Female & Married & $\begin{array}{l}\text { BA } \\
\text { sociology }\end{array}$ & Case worker & $>60 \mathrm{~K}$ & 1 & Only \\
\hline $\begin{array}{l}5^{* * *} \\
\text { (Barbara) }\end{array}$ & 36 & Female & Single & $\begin{array}{l}\text { Some } \\
\text { college }\end{array}$ & $\begin{array}{l}\text { Admin staff for } \\
\text { retirement } \\
\text { community }\end{array}$ & $<30 \mathrm{~K}$ & 2 & Youngest \\
\hline $\begin{array}{l}6 \text { ** } \\
\text { (John) }\end{array}$ & 40 & Male & Married & $\begin{array}{l}\text { High } \\
\text { School }\end{array}$ & Cement Mason & $>60 \mathrm{~K}$ & 3 & Oldest \\
\hline $\begin{array}{l}7^{* * *} \\
\text { (Elizabeth) }\end{array}$ & 31 & Female & Married & $\begin{array}{l}\text { High } \\
\text { school }\end{array}$ & Student & $<30 \mathrm{~K}$ & 1 & Only \\
\hline $\begin{array}{l}8 * * \\
\text { (Jennifer) }\end{array}$ & 47 & Female & Married & $\begin{array}{l}\text { Some } \\
\text { college }\end{array}$ & $\begin{array}{l}\text { Stay at home } \\
\text { mom }\end{array}$ & $>60 \mathrm{~K}$ & 2 & Oldest \\
\hline $\begin{array}{l}9 \\
\text { (Maria) }^{*}\end{array}$ & 50 & Female & $\begin{array}{l}\text { Domestic } \\
\text { partner }\end{array}$ & $\begin{array}{l}\text { BS Sports } \\
\text { medicine }\end{array}$ & $\begin{array}{l}\text { Real estate } \\
\text { agent }\end{array}$ & $>60 \mathrm{~K}$ & 1 & Only \\
\hline $\begin{array}{l}10 \\
\text { (Robert) }^{*}\end{array}$ & 39 & Male & Married & $\begin{array}{l}\text { Law } \\
\text { school }\end{array}$ & Lawyer & $>60 \mathrm{~K}$ & 3 & Oldest \\
\hline
\end{tabular}

Table 1.

Socio-economic category: ${ }^{*}=$ Middle-class, ${ }^{* *}=$ Working-class, ${ }^{* * *}=$ Low-income 


\section{Parent Responses}

In this part of the results section I will briefly describe how the parents I interviewed answered my main research questions, then follow with more in-depth information that fleshes out the responses to my broader question. I follow the brief answers to my questions with a deeper discussion on the theme of role \& power. Next, I discuss how confidence looked for the parents I interviewed, since confidence is part of how I see activation of cultural capital expressed. I then talk about the kinds of conversations parents had with teachers and the ways those conversations helped parents gain confidence. Next, I discuss some of the barriers and supports that parents encounter that affect their confidence in their role. Finally, I discuss the themes of primary parent a theme that emerged from the data and which suggests that family form might also have a role to play.

"How do $5^{\text {th }}$ grade parents in the Portland Metro area understand their role in the parent-teacher relationship?"

In answer to my research question about how parents saw their role in parentteacher conversations I found that parents' feelings about their role were closely connected to how much power they perceived they have in their interactions with teachers. Most of the parents said that they viewed their role to be that of listener, and several of the parents also felt that their role involved reciprocity and that they would both listen and instigate or bring up concerns or issues. Seven of the ten parents I 
interviewed (including all three of the fathers) felt that part of their role was to listen to what the teacher had to say about their child.

"How do $5^{\text {th }}$ grade parents in the Portland Metro area understand the teachers role in parent-teacher conversations?"

In answer to my second question, parents I interviewed described the teacher's role to be provider of information. Parents said that teachers have training and education that gives them expertise and that their role is to both inform parents of academic progress and suggest ways that parents might help at home. Parents also said they appreciated when teachers were aware of social and emotional development and how those added to the equation.

My broader question about activation of cultural capital is answered by looking at the parent-teacher relationship and how the parent's understanding of role and power play out when they describe their conversations with teachers. In the rest of this chapter I will describe the themes that emerged from my conversations with parents and how they connect to confidence and collaboration, the two concepts that I use to suggest that the parent-teacher relationship is a place where cultural capital can be activated.

In my data, I am looking for evidence of three things to suggest activation of cultural capital. First, I am looking for signs that parents feel welcome and accepted by teachers instead of marginalized. Second, I am looking for awareness of knowledge skills 
and language that fits with understanding institutional processes - this might be represented by collaboration and partnership, since common language would be required to form that type or relationship. Finally, I am looking for examples of parents getting the outcomes they ask for in parent-teacher conversations.

Three themes emerged from the interviews that I believe help demonstrate the activation of cultural capital. The themes are role \& power, formal vs. informal conversations and barriers \& supports and along with the concept of confidence; they make up the areas explored in trying to understand my broader research question. The role \& power theme shows how parents understand their role in the parent-teacher relationship and demonstrates their comfort and familiarity with the power dynamics and whether or not they feel engaged or marginalized.

After role \& power I will talk about the concept of confidence and how that looked for parents I interviewed and how it fits in to understanding the potential activation of cultural capital. Confidence was not a theme that emerged from the data, rather it was tied to a question I asked which I thought would give more insight into how parents exercise their power in the parent-teacher relationship. Following confidence, I will look at the theme of formal vs. informal conversations and how those contribute to parents' confidence in their role. I then turn to the theme of barriers \& supports to find out how parents feel access to fruitful conversations with teachers can be facilitated or hindered. I end with the theme of primary parent, which emerged from the data and signifies both the individual who receives whatever cultural capital can be gained from the parent-teacher relationship, and a point of interest for future research. 
Role \& Power

In this section I continue with how parents understand and described their role in their conversations with teachers. Two of the fathers and two of the mothers thought that their role included a combination of listening and acting as an instigator in the conversation with specific goals and direction. One of the fathers and two of the mothers saw their role to be primarily listening while three of the mothers saw their role as primarily that of instigator.

In the context of these interviews I defined the instigator role to include parents who felt they had to initiate conversations with teachers, as well as those who asked questions and challenged their children's teachers to give them more information and to explain the information they were getting in more detail. Robert spoke to this combination of listener and instigator when he said:

I try to ask a lot of questions. And really I am just trying to get a sense of where my son fits within the spectrum... academically and socially and behaviorally. So my role tends to be gathering information just so I can get a better sense of where he is and if he is going off the deep end one way or another in any of those areas. I listen a lot at those conferences and those meetings" (Robert, 39).

The parents I interviewed described multiple roles depending on context and the kind of information being discussed. For example, in a parent-teacher conference they felt they should spend at least some of the time in a listening role while other times they felt that they should "let the teacher know what was going on at home" (Mary, 48). Some of these roles were viewed as positive and some as negative. They felt that they needed to listen to teachers about the academic progress and development because teachers clearly had training and expertise about curriculum that they lacked. In return they expected 
teachers to validate their role as parent by listing to their perspective on their individual children and the larger picture of what might be going on for them.

Examples of parent satisfaction were reflected in both the animated tone of voice they took on when they described their interactions and the words they used about their positive experiences. One parent expressed appreciation for the teacher listening to them in their role as expert when she said "I found them to be very eager to listen, eager to support and they appreciate me letting them know where she is at as far as her spot in life right now" (Mary, 48). Another parent specifically detailed the exchange between two experts when she talked about her relationship with her son's $5^{\text {th }}$ grade teacher in this way:

I definitely expect that the teacher is going to be able to give me a clear picture of what's happening in the classroom. And with my child. I look to the teacher to help with... I can't... I didn't study child education so I expect the teacher to be able to bring ideas to me... how to work with my particular kid... like if there are some aspects of his personality that I can give insight into then that's what I can give, but I expect him to bring whatever he has learned in getting that education and getting that experience. So ... I think that puts a lot on the teacher because you know, he's dealing with people who don't have that education background. I think one example that would be some of the core curriculum things that they are doing. Like with the new way that they are teaching math. So I need him to explain that to me. I need him to provide that background. I can tell him this is how I see this person being able to work at home... these are the kind of things that are frustrating... but I need him to tell me this is the process, this is how I have seen things working with other kids. I can only tell him about this one little person and that's from a mother's perspective on relationship, that's not like from someone with a degree in childhood education. (Linda, 36)

In her explanation, Linda is acknowledging the teacher's expertise and education validating the role of teacher. At the same time, she is clear about her contribution and expertise - her insights into her individual child. Linda and Mary are both describing 
situations in which they feel empowered in their relationships with teachers, that they have valid and valuable contributions and that the teachers appreciate their insight and incorporate the information they get from parents. Linda is a middle-class mom and Mary is a working-class mom and neither one of them feel marginalized in their dealings with teachers.

In two cases the parents felt that they had to be the instigator of conversations when they had concerns about their children and that seemed to be a point of irritation. The feeling that they had to instigate a discussion might happen outside of a formal conference, if they felt like the teacher needed to be aware of something going on for their child, but they also sometimes mentioned feeling like the instigator within the formal parent/teacher conference. They also felt frustrated if issues that their kids were having were brought up for the first time in parent-teacher conferences. Parents felt like they were blind-sided if the teachers had given them no prior warning.

One parent mentioned that her son's current teacher is really good about communicating, but that she had difficulties in past years and she gave an example of frustration with the role of instigator. "In years past it kind of has bothered me to feel like I was the one to either drag information out or only hearing when there was something bad going on and that I needed to fix it" (Linda, 36). This comment also alludes to the frustration that parents can feel when they see themselves as "blind-sided" by information about their child.

Another parent talked about the problem with being blind-sided or taken by surprise when she explained "Well sometimes I think that we have felt, not blind-sided... 
but just a little bit of oh... you're now just bringing this up instead of maybe an email or a phone call to say that 'we have had this issue a few times' instead of just bringing us in and puking all over..." (Jennifer, 47). Jennifer is a working-class mom and Linda is a middle-class mom, but both of them point to moments of frustration when circumstances get in the way of effective communication.

Although nine out of the ten parents I interviewed revealed some level of satisfaction with at least some of the teachers they interacted with, one of the parents felt strongly that she was not in a collaborative relationship. She also revealed that she didn't have a clear view of what her role should be, “I guess I don't know what my role is supposed to be. I feel like my role is... like I am lead to believe my role is just kind of to listen and go home" (Patricia, 42). Patricia is a middle-class mom, but she feels frustrated and seems unable to utilize her cultural capital.

Parents feel a broad spectrum of roles as a result of their conversations with teachers. They start out as a "listener" but as they develop more confidence in their role they feel empowered to ask more questions. Parents with frequent communication described the parent-teacher relationship as a partnership and said they hoped for collaboration. James describes the importance of collaboration when he says:

Collaboration would be the word I would like to use. Because again... they're the leader, they're spending all the time. But their vested interest is maybe about a year and mine is a lifetime so... let them preform their role, but I would strive for it to be a collaboration. I don't know if it realistically ever gets there, but that's what I would like to see (James, 40).

When James talks about collaboration, he is suggesting a relationship in which both parent and teacher have important contributions and insights. In collaboration, I think 
parents can be seen to be activating their cultural capital because they are working toward shared goals with teachers and there is some ownership and empowerment in the process.

I asked the parents specific questions about things that helped them in their role and things that challenged them in their role. They answered those questions directly, but some of the things that helped or hindered them also came out when they were talking about their role, the types of conversations they have and the most meaningful conversations they had with teachers. I found that nine of the parents I interviewed, including all of the parents who fell in working-class and low-income categories, spoke of gaining confidence in their role over time. Early on I felt that confidence in role could be connected to activation of cultural capital so I asked parents specifically if they felt that they had gained confidence through their conversations with teachers and nine of them replied that they had.

\section{Confidence}

Initially I asked parents about how their conversations had changed over the years, but after my first interview I got more specific and asked if the conversations they had with teachers over the years had increased their confidence in their role within the conversations. One parent (Patricia) expressed only increased confusion in her role and described herself as "jaded" about the public education to which her son has access. All of the other parents expressed an increased confidence in their role and several of them gave specific details. 
James described his ability to "ask the difficult questions" after he gained confidence in his role from the conversations he had with teachers over the years. He said he lacked the confidence to ask those questions before. "You know why is the math curriculum so weak? I ask that now. I've been thinking it for years, but I actually ask that when I talk to the teachers now. I would definitely say there was a little bit of a learning curve and a comfort curve going through this" (James, 40).

James also spoke of a situation with his second daughter in which he suggested to her teacher that she be tested for the advanced curriculum. He explained that a previous teacher had tested his daughter and she didn't pass, but the next year she seemed bored. In light of this, James decided to broach the subject with his daughter's current teacher and was able to get his daughter tested again, but there was a trade-off:

I kind of regret this because I am never going to get the second grade teacher's unadulterated opinion of my daughter's ability because I put it in her head first. Anyway... the converse of that is she's going to be tested again and the second grade teacher is going to do some enrichment activities with her (James, 40).

James was able to activate his cultural capital and get what he wanted - his daughter would be tested again. James is a middle-class father so this does fall in line with existing literature on activation of cultural capital. It is interesting to note that James is also reflecting on his own power and is conscious that there is a loss from not "knowing the teachers unadulterated opinion" of his daughter's capabilities.

Even though James feels that he might have been hasty in his suggestion, I still count his interaction as collaboration - one that ultimately worked in his favor. He activated his cultural capital and used it to gain an outcome he desired for his child. Nine 
of the parents talked about this learning curve and those parents also expressed that their conversations with teachers got more collaborative as their confidence increased.

Even though parents felt more supported in their role when their interactions with teachers were positive, they also found the negative interactions constructive. Sometimes the parents described negative experiences as a sort of testing ground where they learned that they needed to be more assertive or ask more questions. Barbara describes this when, after talking about some differences of opinion with her daughter's third grade teacher, she goes back to that negative experience as a point of reference. When asked if her confidence in her role has increased as a result of her of conversations with teachers over the years Barbara responded "Yes. Especially the last two. Like I felt like I wasn't getting through to the 3rd grade teacher" (Barbara, 36).

Barbara is a low-income single mom and she equates "getting through" to a teacher as being able to get what she wants, validation of her role and attention to the areas of her daughter's curriculum and growth that she is most concerned about. Although she expressed some of the same learning curve described by other parents, she said that she started off with an advantage because she has an older daughter and went through the process once already. Even though Barbara spoke of a teacher she was "unable to get through to" she views it as a situation that was particular to a specific teacher, even citing "cultural differences" because the teacher is from the United Kingdom.

Parents talked about other ways they experienced the learning curve toward confidence in parent-teacher relationships. Maria referred to comfort with process as 
essential to part of the learning process and her ability to gain confidence in her role. She described the "daunting" feeling that she had when her daughter was entering kindergarten and how her familiarity with the process has been helpful when she says:

Certainly feel like I have gotten more comfortable with just the idea of having conversations, that it's a big.... You know starting that kindergarten year and then progressing through can be a little daunting to a parent. Now I feel really comfortable. I think it's just the familiarity with the school and with the rest of the staff (Maria, 50).

In her statement, Maria confirms that familiarity over time has helped her gain confidence in her role and specifically that this familiarity has increased her comfort in having conversations with teachers. Part of her comfort comes from assurance that teachers will take what she has to say seriously, a sign that her cultural capital is activated.

In addition to their conversations with teachers, parents referred to the process of gaining a deeper understanding of their child and how their child performed while at school and how that played into their confidence within parent-teacher conversations. Jennifer elaborates when she says that the conversations with teachers helped, and explains further "Definitely, yes, I would say all of that helps. Because then you actually have a background on your child because you are trying to get to know them as a person too and where they are coming from" (Jennifer, 47). Robert developed this connection further when he described this interaction between knowing his son and understanding the process in his response to my question about confidence in his role.

Yeah because like I said I am more confident in.... I guess I just know the issues now. When you first sit down with your child's first teacher you have no idea what to expect. It could be anywhere on a spectrum from good to bad on every issue. So I am more confident now that I know my 
son better. I know what he is good at and what he needs help with and that has stayed very consistent throughout his school years and so I am confident that I know what to ask... that I know what to not ask or not worry about. We have been able to focus our attention better on just a small number of things that we feel need to be addressed and we don' $t$ ' waste our time with other things that we either don't find as important or that we know he doesn't need help with (Robert, 39).

Robert specifically refers to conversations with teachers as a place where he learns how to have constructive conversations that reinforce his role as parent within the parentteacher relationship. He talks about knowing his son better and about understanding the process more. His conversations with teachers over the years have helped him build confidence in his role.

Jennifer is a working-class mom and Robert is a middle-class dad, but they both described their conversations with teachers as collaboration and were confident in their ability to participate constructively in their conversations with teachers. Jennifer described a possible marker for this collaboration and ability to feel effective in the conversation as "getting on the same page." She says, "basically after a while in that immediate conversation... where we may be coming in from two different places and after a while we start clearing up some things with each other about whichever child we are talking about its like "ok, now I get where you are coming from" (Jennifer, 47). Jennifer described getting on the same page as a place where she can actively impact her children's experience through conversation with teachers and this suggests empowerment and activation of cultural capital. If she were not able to activate her cultural capital, it may be that Jennifer would feel that she never got on the same page with teachers.

Linda talks about how the confidence she has gained over the years has shifted her role in the conversations. She explains, "I ask a lot more questions, right from the 
beginning. I don't worry about bothering the teacher. I'm also much more confident in bringing my own views and opinions to it, not just accepting the views and opinions of the teacher" (Linda, 36). In her remarks, Linda is reflecting on the confidence she has gained in her role and also her increased sense of power to actively participate in the process with her son's teacher. Linda says that the teacher's acceptance and encouragement of her involvement, as well as the positive feedback she receives, makes her feel a higher level of trust and that she can work more effectively toward the goals she has for her son. She is a middle-class mom, so it fits with the existing literature on middle-class parents being able to activate capital, but she also spoke of earlier years where she felt frustration and like there were too many negative comments - a sign that her cultural capital had not yet been activated.

Thus far I have discussed the fact that nine of the parents I interviewed felt an increase in confidence as a result of their conversations with teachers. I have talked about some of the ways that their confidence could be seen as connected to activation of cultural capital and I have shown that parents in all social classes experienced confidence in ways that could be seen as possession and activation of institutionally valued cultural capital. In the next section I look at formal and informal conversations as sort of training grounds that help parents understand and use their role and power more effectively.

Formal vs. Informal

The confidence that parents gain through conversations with teachers can only be connected to activation of cultural capital if parents feel that they are better able to gain 
beneficial outcomes for themselves and their children. One way to explore if parents feel empowered is to look at whether or not they see their relationship with teachers as a partnership or collaboration. When analyzing my data, I found that the level of partnerships parents perceived could be viewed through the amount of formal and informal communication and how they felt about those conversations.

When I asked parents about the kinds of conversations they had with teachers, their answers fell along two trajectories. One was a range from formal to informal and mainly this was based on timing or location. The other trajectory had to do with whether the conversation was topically based on home or school. Parents acknowledged the fact that children moved back and forth between the two environments and that their success in one environment was related to what was happening in the other. One mother described the divide between home and school based conversation in this way:

Um, well let's see... within the last couple of years, it's been to just let the teacher know what's been going on with the family as far as the parents are concerned. Because recently my husband and I have separated a couple years ago and we are still going through the proceedings and what not to figure out the best schedule for the kids and that kind of thing. So, I have been trying to make sure that I have been keeping teachers on the same page as far as the family goes. So we have been having those conversations.

Secondly I've been trying to monitor how academic performance is progressing or not progressing. What kind of behaviors they are noticing, that kind of thing. So mainly its just been focused on making sure that she is at the best spot that she can be as far as being a student is concerned.

I've been trying to keep the lines of communication open with her teachers and that kind of thing. Not trying to repeat myself or anything... but just making sure that we are all on the same page, as we go down this path. So far she is doing fine, she is doing great. Her teachers have always said she is very bubbly... very social... she is exceeding at math and reading...and she is still real excited about school... wants to be there, wants to learn. (Mary, 48). 
In her response, Mary is defining both the conversations and how she perceives her role within them. She emphasizes the importance of focusing on both school and home within the conversations and she demonstrates her involvement as an active participant. The partnership Mary describes can only be effective if she is activating her cultural capital. She feels empowered in her role and comfortable with her place in the conversations she has with teachers.

When I asked parents to specifically explain the kinds of conversations they participated in with teachers, they all mentioned parent-teacher conferences as the main formal interaction, but they described other avenues of conversation as well. One parent stated, “...So email is super prevalent. They do a newsletter every week that comes out and we did just have curriculum night about two weeks ago which was I think only my second face to face time meeting my daughter's fifth grade teacher" (James, 40). When James describes email, curriculum night and newsletters he is describing mostly formal means of communication - although some informal conversations can take place within these settings. Newsletters are formal and also one-way communications between teachers and parents. However, items in the newsletters might spark a conversation. Curriculum night presents an opportunity for parents to see what the teacher has planned for the year and the way they will manage their classroom, but it also creates an opportunity for side conversations and just "getting to know" each other and initial relationship building. In my interviews, email stood out as an important method of communication that is growing in prevalence. 
I believe that email was seen as a sort of midway communication between formal and informal. Some of the parents described it as a way of following up on conference issues and others mentioned it as a means of informally checking in about how kids were doing. One parent referred to the follow-up aspect of email when she said "If there are follow-up conversations needed I would email the teacher or make a plan to meet at drop off, if I wanted a more in-depth conversation I would arrange meeting after school at pick up time" (Maria, 50). Another parent described the more informal aspect of email when he said:

I almost think that email would be used for less serious things. More trivial like 'hey, my son is going to be on vacation next week' or 'we didn't get the assignment, can you send it to us?' I think with talking about students or kids in school... it's not nuanced enough to do it by email and so having that conversation personally works best" (Robert, 39).

Informal conversations were mostly centered on pick-up and drop off and usually these happened more in two parent households with a primary parent. However, informal conversations also included informal interactions that might happen on curriculum or back to school night, when visiting the school to investigate the curriculum and side conversations that occurred when volunteering.

Conversations about school and conversations about home could be had in either a formal or informal conversation. Parents sometimes described the formal meeting as an information exchange where they informed the teacher about what is happening at home and they received information about what was happening at school. Parents said they got information primarily about academics at the conference, but they said they asked 
teachers about social and emotional wellbeing at school and appreciated gaining that feedback as well.

One parent addressed the combination of academic and social conversation when she said of her daughter's teacher 'I'd say that she keeps me aware of academically what my daughter is doing. But she also covers social interactions and progress of my daughter socially" (Barbara, 36). Another parent revealed "I always do ask how she is doing socially because she is quiet and you know she's in the challenge program... she's in a group of nerdy introvert kids so I make sure that she is also interacting" (James, 40).

Almost all of the parents I interviewed felt that one conference was not enough for the school year. As mentioned before, of the 10 parents interviewed, only one parent saw the single scheduled conference a year as adequate. Two of the parents mentioned that their kids had Individual Education Plans (IEPs) and that these dictated additional conferences throughout the school year. When I asked for an explanation of IEPs I was told that they are developed in concert with physicians when children have special needs.

In cases where an IEP exists, additional formal conferences are required to be scheduled. Parents can also ask for additional meetings even if they don't have an IEP. Linda said that although she doesn't have and IEP, she requested and received an additional conference with her daughter's teacher. It is interesting to note that while parents can ask for additional conferences and almost all of them felt that one wasn't enough - only one of the parents asked for an additional conference with her child's teacher. I asked parents if they felt that teachers were available to them if they had 
questions or concerns and they all said yes. However, they noted that teachers have limited time - this is one reason that I believe email is so important.

Maria talked about her frustration with the single scheduled conference, while at the same time acknowledging the difficulty of the time constraints felt by teachers:

Well, I know they are pretty time consuming for the teacher, but it seems that maybe quarterly or at least twice a year. Maybe the early fall conference and maybe an early spring or somewhere before spring break. Kind of like where you are at, but not waiting until the end of the school year because that's just kind of a post assessment, not really a midterm time. The first fall conference is... I see how teachers use it sometimes as setting up "here's what we do in school" but that's kind of an open house thing. I don't know... when do we have the first conference, thanksgiving... no we had them on Halloween this year so that's even earlier than we have had them in past years. It's sort of like you've known my kid for a month and what do you really have to tell me (Maria, 50).

Maria is very clear that she would like an additional conference in the spring and she is clear about the benefits of a possible spring conference and that it shouldn't be too close to the end of the school year. Still, she doesn't ask for a second conference.

All of the parents I talked to without exception either wanted more access to teachers in some way or felt confident in their ability to ask for more conversations if they wanted them. Patricia, who expressed ambivalence about her role and frustration with the school system, still expressed an interest in more involvement even though she thought it would be unlikely to happen. "I don't know what is going on in the classroom, but I would like to know" (Patricia, 42).

A formal conference is a place where the power dynamic is very much in the teacher's favor and informal conversation seems like a safe space to build the relationship and trust. Trust and confidence were both concepts described by parents when they 
started talking about their perception of their role and how they felt about conversations with teachers. From the parent narratives it is clear that, for at least the parents I spoke to, the conversations they have with teachers helped them gain confidence in their role as parent within the parent-teacher relationship.

Parents either referred directly or indirectly to informal conversations as being the most meaningful communication with their children's teachers in two ways. On one hand there were informal conversations that happened in spaces outside of class where a parent felt connected in a deeper way and felt more understood by the teacher. On the other hand a different parent explained that the frequency of informal interaction helped him when it became time to meet formally, because he felt more comfortable. James described why the informal communications around pick-up and drop-off were so helpful when he said:

The waving to the teacher in the hall... Going to the after school activities. It's easy to sit down and have the formal... the curriculum night or the parent-teacher conferences... that's a pretty formal structured environment. To have some informal interactions I think that's more valuable to make the formal ones easier and comfortable. I'm picking up and dropping off the kids every day and waving to the teachers... I'm like Mr. mom. I like that part. It makes it easier to talk to these people (James, 40).

James is very clear that the informal communication and conversations are so important because the make the formal ones easier and more comfortable. In other words, the informal conversations increase his confidence in performing his role.

James and Patricia are both middle-class parents, but their level of confidence is markedly different and so is the frequency with which they communicate with their children's teachers. James communicates often and in a myriad of ways - he is in charge 
of pick-up and drop-off, he attends the school events, he emails the teachers and he asks pointed questions at the formal conferences. In contrast, Patricia communicated seldom she feels that her attempts to engage are thwarted and she is ambivalent about the processes surrounding her son's education. The different experiences of these parents seem tied to the frequency of communication, both formal and informal. This suggests that more frequent communication can be helpful in activating cultural capital, although there are most likely other factors involved.

One of the opportunities for informal conversations with teachers happens on field trips. When parents volunteer to go on field trips with their children's class, they find themselves in situations where they are outside the classroom, in a different type of activity and they are working closely with the teacher to makes sure the trip is successful. One parent described a particularly meaningful, informal conversation and how much of an impact it had on her in this way:

The field trip was a good experience with the teacher because she kind of came down to my level is what it felt like. We were just on the bus going down to the theater and she pulled me aside and looked into my eyes and said "hey, I just want you to know that your son did this... and it was really cool." And she didn't really have to point that out or anything... or even notice, but she did and you could tell that she really appreciated that, was really involved with the kids. (Elizabeth, 31)

Elizabeth is very clear that part of what made this communication so meaningful is that she felt as though she and the teacher were on equal ground. She felt validated in her role as parent and that she was recognized for the part she plays. The informal connection she had with her son's teacher helped her gain confidence in her role and the memory of it stayed with her. She remembered it even two years later. Elizabeth is a lowincome parent, but her interactions with her son's teachers have helped her feel 
empowered in her role in the conversations she has with them. She feels validated in her role and confident that teachers are receptive to her involvement.

Informal conversations such as those had at pick-up and drop off develop a comfort with teachers and help parents feel "more comfortable in the more formal conversations." Deeper level informal conversations, where teachers "got down on the level" of parents, increase confidence by validating their role. Formal conversations are places where parents can work with teachers to help further their children's academic goals and the increased opportunity for formal conversation provided by email can help parents keep the conversation going, gaining confidence with increased interaction.

In my study I felt that the frequency of conversations with teachers was a key factor in how confident parents felt in their role and how empowered they felt in their ability to act on their children's behalf. Email then surfaced as a very interesting avenue of possibility because it allows parents to overcome barriers of limited time and disjointed work schedules. If lack of time constituted a barrier, then it is possible that email can help knock that barrier down.

\section{Barriers and Supports}

In this section I will describe the barriers and supports that parents reported in their conversations with teachers. These barriers and supports could be seen as ways that opportunities for confidence building are either reinforced or hindered. One of the most significant barriers parents described was the lack of time that teachers have and the small number of formal conversations they are scheduled to attend. According to the 
parents I interviewed, the elementary schools in the Portland metro area schedule just one conference per year, in the fall. All but one of the parents felt that this number was inadequate and most said they would like to see at least two conferences.

One of the parents brought up the insufficient number of conferences twice, once when I asked about how she felt her role was supported and she replied "Sitting down and having a conference one on one regularly... should almost be more regularly... you know" (Elizabeth, 31). She brought up the issue again when asked directly about whether or not she thought the number of conferences was enough and she stated clearly, "No. I feel like there should at least be two. An end of year prepare for next year thing, you know?" (Elizabeth, 31).

A different parent said that although he would like to see two conferences, he did not want to see that time carved out of instructional days. He expressed his conflict about the benefits and drawbacks when he said:

Well that's a tough question. I would love to have more conversations with my kid's teacher about him, but I don't want to take more time out of there.... I guess I don't' want more days off for my kid either... I don't want to carve more days for teacher conferences. I think those conversations are really helpful so I guess... I don't think another formal conference would be necessary, but I guess what I am saying is maybe I just need to have more conversations with the teacher and maybe that would be more helpful. (Robert, 39).

Although the parents identify the small number of formal conferences and time constraints as a barrier, they seem to feel that email might help mediate that obstacle and therefore see email as a means of supporting their role. Parents made reference to the importance of email and follow-ups. They trusted and felt confident in their relationships with teachers and their role within that relationship when the lines of communication felt 
"open." They mentioned several times the importance of "getting on the same page." It was more challenging for parents and they felt discomfort and marginalized when avenues of communication seemed turned off and like teachers did not have time or did not want to bother because their kids were "doing fine." In my study only one parent voiced feelings of marginalization and frustration on a long-term basis. All other parents spoke of frustration during their "learning curve" - and this was true of middle-class, working-class and low-income parents - or in specific instances or with specific teachers. In those specific instances parents were able to resolve their frustration with time and experience or when dealing with new teachers.

Parents felt supported when teachers validated their role as a parent, when they had ongoing positive interactions and when they felt like they were on the "same page" with teachers. Parents felt barriers when they viewed the teacher as overworked, unavailable, and when they felt like all of the interactions were negative. One mother expressed this specifically when she said:

I don't feel like they really want to take the time to talk about one kid. I feel bad I feel like I am throwing them all under the bus, but I think they are overworked and they have so many standards to meet and all that stuff that, you know, my son is fine. He is doing just fine. He's not a problem kid. He's not you know... So it's just sort of shut up, everything's fine, we don't have time for this. We have bigger fish to fry... Is my sense. It's not like we really want to give him the best education we can... it's like he's fine... don't worry about it (Patricia, 42).

In her comment, Patricia is detailing one of the barriers she sees to her successful interaction with teachers. She believes the teachers don't have enough time and thus her son gets short-changed. She seems to lack confidence not only in her own role, but also in the teacher's ability to perform theirs. She also appears to lack trust and I believe this is a 
barrier to her getting the positive feedback that might help her gain confidence in her role and work toward more of a partnership or collaboration.

One of the mothers spoke at length about how important positive feedback is in helping her feel confident and able to trust her son's teacher. When I asked her to tell a story about an interaction that stands out for her, she told me about an unsolicited positive email that she got from her son's teacher on the first day back to school at the beginning of the year.

I thought that this is the first time that this has happened...that I have gotten this type of email the very first day and it has set the tone for the entire year. This has been the best year so far and I let my son know that I got that email and it's been much better... much better. Because that means a lot for him too because I tell him when I get emails from teachers good and bad so with this teacher its just been so much more positive than negative. And it stuck out because that's the first time that has happened (Linda, 36).

In our conversation Linda also revealed that the positive feedback she has received from the teacher her son has now has allowed her to "relax her guard" and trust that what she says will be taken seriously, further indication of activating cultural capital. With the increased trust she feels, Linda feels that the lines of communication between her and her son's teacher are more open and productive.

The idea of open lines of communication and getting on the same page showed up in multiple interviews. Mary talks about "getting on the same page" when she talks about how she views her role. Other parents talked about getting on the same page and the importance of getting there in order to have a productive conversation. Jennifer mentioned that things went smoother after communication was established and "I think after a while we are all on the same page" (Jennifer, 47). I asked Jennifer about how long 
they spent at a conference getting on the same page and she estimated that initially (at the first few conferences) it took about 10-15 minutes, which is about half the time scheduled for the meeting. This suggests that relying on the formal conference alone for parentteacher communication would seriously hinder the relationship and the opportunity for parent's to activate cultural capital as a result of their interactions with teachers.

While lack of communication and negative conversation were perceived as barriers, positive and "meaningful" conversations with teachers seemed to be perceived as supportive. Parents describe the most meaningful conversations with teachers as those that included positive communication and also follow-ups for specific discussions. Parents were also highly impacted by communications around what they perceived as major transformational times for their kids. These included entering the public school system with kindergarten and the anticipation of transition to middle school.

One parent expressed that positive communication was a boost to parent confidence. In her response, she spoke about the impact of both negative and positive comments from teachers. She also emphasized that the combination of both helped make the parent-teacher relationship more solid in this way:

Having the conversations about what's going well is very helpful. I think it's just a confidence boost to feel like... if all you get is negative reports then I think that it makes you lose confidence as a parent and then just kind of makes you feel like you don't know what you're doing so what can you contribute to this situation. So I think having these... getting the good and the bad just makes me feel more confident to have discussions with the teacher in general. (Linda, 36).

Another parent mentioned the helpfulness of the combination of good and bad feedback from teachers when she explains: 
Definitely positive feedback and if you have had communications in the past where we are using certain tools to help our child and they say "wow, I'm really seeing some improvement" or "this looks good and this looks good but he needs to really start wrapping up on this" It's kind of that sandwich where it's positive negative positive is I think a good way to go. (Jennifer, 47).

Both Linda and Jennifer are talking about building trust and learning that they can count on teachers to give honest evaluations of their children. They both see the combination of negative and positive feedback as evidence that they can trust their children's teachers and they offer their trust in return. This contributes to a collaborative relationship, which increases the possibility that cultural capital can be activated.

When asked about other challenges they experienced in reference to the parentteacher relationship, two of the parents cited "old school ideas" held by some teachers about family structure. Both of these parents were in "non-traditional" same-sex partner ships. One of the mothers mentioned that the challenge specifically had to do with the teacher's acceptance (or lack there of) when it came to their family form. She explained "My daughter has two moms and ... felt like we sort of had to remind the teacher that using phrases like 'take this to your mom and dad' weren't maybe as inclusive as she could be considering that not all of her students had moms and dads" (Maria, 50).

In addition, some parents mentioned issues they had with curricular decisions. In one instance a single mom talked about how she felt there was curriculum missing when her daughter was in third grade. "I found it challenging to try to speak with the teacher previously about why she wasn't implementing what I thought to be important curriculum at her age... at all, the entire year. That was challenging. I haven't found anything this year" (Barbara, 36). In another instance (mentioned earlier) one of the 
fathers (Robert) mentioned that he acted as a mediator when his wife had problems with the way his son's teacher delivered certain curriculum.

Issues of social class didn't surface when I asked the parents about challenges particular to them, but one parent did mention social class as an issue when talking about other backgrounds in a diverse classroom setting. His concern centered on the environment children in lower SES households deal with. He cited this as a particular concern and something that he didn't know how to address with the teachers within their conversations:

We're comfortable and my daughter is fed every morning when she gets there, she has clean clothes all the supplies she needs and there's other kids that aren't and that's just part of it... the kids that have to go to free and reduced lunch, that sort of thing. Those poor kids maybe didn't get a good night sleep. Maybe they're single parent families. But they might not have a safe place at home and it impacts them at school and then here's where it gets frustrating. My daughter comes home "Oh we got a 3 out of 5 in music today" which means they had to put their heads down for 15 minutes and be quiet because some kid was acting out today and impacts my daughter and that's uncomfortable so what am I supposed to do? Come in and yell at the teachers or the administrators or whomever and say you know he disrupted the classroom I don't know anything about this kids background but he's disrupting my daughters learning environment. Sorry, I'm a little passionate about this one... it's very uncomfortable and no I'm not going to put them in a little isolated box and send them to private school either, but that entire topic is extremely uncomfortable... easy to vocalize between friends but try to tell that to a principal or a school teacher and all she can say is I'm doing my best and my wife always wants to reign me back in those conversations because there's nothing you can do, it's public school (James, 40).

James feels constrained by his inability to talk about his concerns with his daughters' teachers. He acknowledges that it is important for children to learn about different backgrounds and doesn't want to deprive his daughter of the opportunities of 
understanding that different people have different resources. However, he perceives a barrier when talking to the teacher because he doesn't feel like he can effectively change the circumstances of students with less resources and he doesn't know what can be done if the lack of resources that some children experience has a negative impact on the classroom. None of the other parents mentioned this concern as a barrier to talking with their children's teachers.

Even though parents acknowledge the lack of available time for conversations with teachers at school, they still seemed to feel support for their role because of the availability of email as an option. On the subject of email one parent said she likes email because "It's just convenient for everybody and also if it's because of a problem I think its easier for me to be able to sit and think exactly what I am trying to communicate and what I want to say. I like the email also for the convenience of it" (Linda, 36). In this comment Linda is expressing an appreciation of email because it is convenient, but also because it allows her time to think about her response and think more carefully about how she wants the conversation to proceed.

It is not just the teachers who are squeezed for time, parents themselves refer to their busy schedule and express an appreciation that email offers them a way to be more involved than their schedule would otherwise allow. One of the fathers explained this important function of email when he stated:

Email is easier for them, it's easier for me... that allows some tracking it allows us to have a little bit of thought rather than just saying hi how has your day been. I think it's more structured. I would say over the past two or three years it's gone from a little email to almost predominantly email. (James, 40). 
James also explained that when he emails teachers they respond within a few hours or the next day. When he emails, it is because he has a concern he wants addressed and he is satisfied by the response time and the attention teachers give to their responses. I believe this is an example of activation of cultural capital - James knows that teachers are available and responsive and he feels empowered in the exchange.

Even though Patricia seemed frustrated by lack of time with teachers and limited conversations, she did mention that she appreciated email as a meaningful mechanism for communication:

I like when they do an email or in 4th grade she had a blog... which was good, but it was hard to remember to check it all the time so email is nice. Some of them have done a newsletter... I like email. Just because it can keep me updated... this is what we are doing, this is what's going on... this is what the challenges are. I would like a little more communication other than these worksheets...Its confusing... don't help them with their homework then help them with their homework and you don't know what you are supposed to do. (Patricia, 42).

Although Patricia was expressing her frustration with the level of communication she experiences, she does note that blogs have helped her maintain a sense of the classroom when her life is hectic and email seems beneficial for the same reason. She also reports frustration because she can't figure out how to help her son at home, something she would like to learn from his teacher.

Parents reported that they expect teachers to be able to help them with understanding what to do to help their children at home - and that when this expectation is fulfilled; they feel supported in their role. For example, one parent described how important it is for her daughter's teacher to give her insight into how to be helpful at home. "How can I help her at home, what can I do to support her outside of homework . . 
. you know ... what resources do I have if she needs it, how can I better assist her to get her homework done or assignment done... that kind of thing" (Mary, 48). In addition, when asked what conversations she found most helpful to supporting her role - Barbara's response echoed Mary's concerns when she replied, "I think probably the conversations we have about my daughter academically, support my role in supporting her more academically.” (Barbara, 36).

In her earlier comments Patricia had expressed interest in hearing from the teachers about how to help her son at home. She is frustrated that she has not been able to get teachers to help her with ideas about supporting her son academically at home - an example that her cultural capital is not activated. In contrast, the other nine parents I interviewed listed finding out how to help their children at home as something they wanted from teachers and those parents all stated that they were satisfied with how teachers responded - suggesting that their cultural capital might be activated.

Figuring out the questions they should ask in order to get the support they needed from their children's teachers is something that parents reflected happened over time. In their stories parents talked about growing confidence in their role and how that confidence changed their conversations with teachers and made them more helpful. The confidence they gained helped them ask questions that they felt were important for their understanding of how to help their children succeed. They felt more confident in the process of shared conversation and valued the interaction with teachers as a connection to their children's learning. I would argue that the confidence and ability to work for their 
interests in parent-teacher conversations is a sign of activation of cultural capital. However, only the primary parent has access to this mechanism for activation.

\section{Primary Parent}

Primary parent is a concept that emerged from the data. The narratives of the parents I interviewed showed that co-parenting does not mean that parents have equal parenting responsibility. One parent is primarily responsible for the relationship with school and as such receives the benefits that come with frequent communication with teachers. Parents who weren't primary seemed to feel disconnected from the day-to-day happenings and seemed less aware of what was going on at school. Non-primary parents in two parent households relied on their spouse to get them up to speed, but single parents without time had no one to catch them up. Only two of the parents I interviewed considered themselves to be non-primary parents and both of them were fathers. However, one of the fathers did emphasize the importance of at least one parent taking on that role.

James explains the need for a primary parent when he says "You've gotta read the newsletter and you've gotta attend the curriculum night any fairs they have the science fair that sort of thing somebody has got to be there and that happens to be me in our relationship and I'm totally okay with it" (James, 40). In this statement John is recognizing a role that at least one of the parents needs to fill. In his case he fills that role, but in all of the other interviews I learned that a mother - either working outside the home, or in a stay at home situation, took on the role. 
One of the fathers I interviewed described the primary role by noting that he is not the parent who fulfills it, "My wife is probably the primary communicator between our teacher and us. Mostly because she doesn't work and she picks the kids up from school and she has opportunities to talk with them personally at that point" (Robert, 39). Robert expressed confidence that his wife would inform him of anything he needed to know outside of the formal parent-teacher conference.

I found that when I interviewed parents who were part of a marriage or domestic partnership, there was one parent who consistently acted as the primary parent. Of the three fathers I interviewed, two referred to their wives as the primary parent and one described himself as the primary parent. The father who described himself as the primary parent was married to a teacher and recognized that this relationship gave him a unique perspective on the parent-teacher dynamic. "I'm just going to full disclosure... my wife is a teacher. So I get the 'Mikey did this today' every single night when she gets home and 'Mikey's parents never showed for their conference' so I hear both sides of it" (James, $40)$.

The two fathers who explained that their wives were the primary parent had different perspectives on the arrangement. Although both described their main role in the relationship as participating in the parent-teacher conferences, they had different levels of participation outside of that. John said that he mainly left everything else up to his wife and that he went into the conference as a "concerned parent." Referring to his wife's primary role, John explains "My wife mostly does the communication with the teacher. Obviously because she's dropping them off and, if there are any issues or any questions, 
she asks the teachers. I think I just met her the first day of school and that was pretty much it" (John, 40).

On the other hand, Robert said that he sometimes acted as a mediator between the teacher and his wife over differences to do with the curriculum, and that he had participated in some email dialogue with teachers. "I don't agree with my wife on some of those issues or I don't think it's as big a deal. So for me it's trying to manage trying not to get bogged down in those issues and trying to steer the conversation toward the real issue or what I think are the most important things" (Robert, 39). Robert also expressed interest during the interview in increasing the amount of communication between himself and teachers. "I still feel kind of a pull about wishing that I knew more about the day to day stuff that's going on" (Robert, 39).

Unlike Maria, the other mothers did not specifically refer to themselves as the primary parent, but they speak about their role as one of authority. For example Mary talks about her role as being one of command when she says "I'm the person who steps forward and says okay, here's the situation and the kind of person who is letting them know what's going on, in case anything does happen... rather than them noticing something and them coming to me to ask 'okay, why is she behaving in this way?' So I am the instigator of the conversations. Does that make sense?” (Mary, 48).

In her remark, Mary is talking about the power dynamic she experiences with teachers, as well as defining the territory of conversations and her primary position within that territory. Mary is a working-class mother, but she feels confident in her role as parent and confident in her ability to communicate with teachers effectively. She expects that 
teachers are "responsive, via email and parent-teacher conferences... providing me with feedback because I am not there with her all the time" (Mary, 48).

Thematic Diagram: Theme contribution to parent confidence

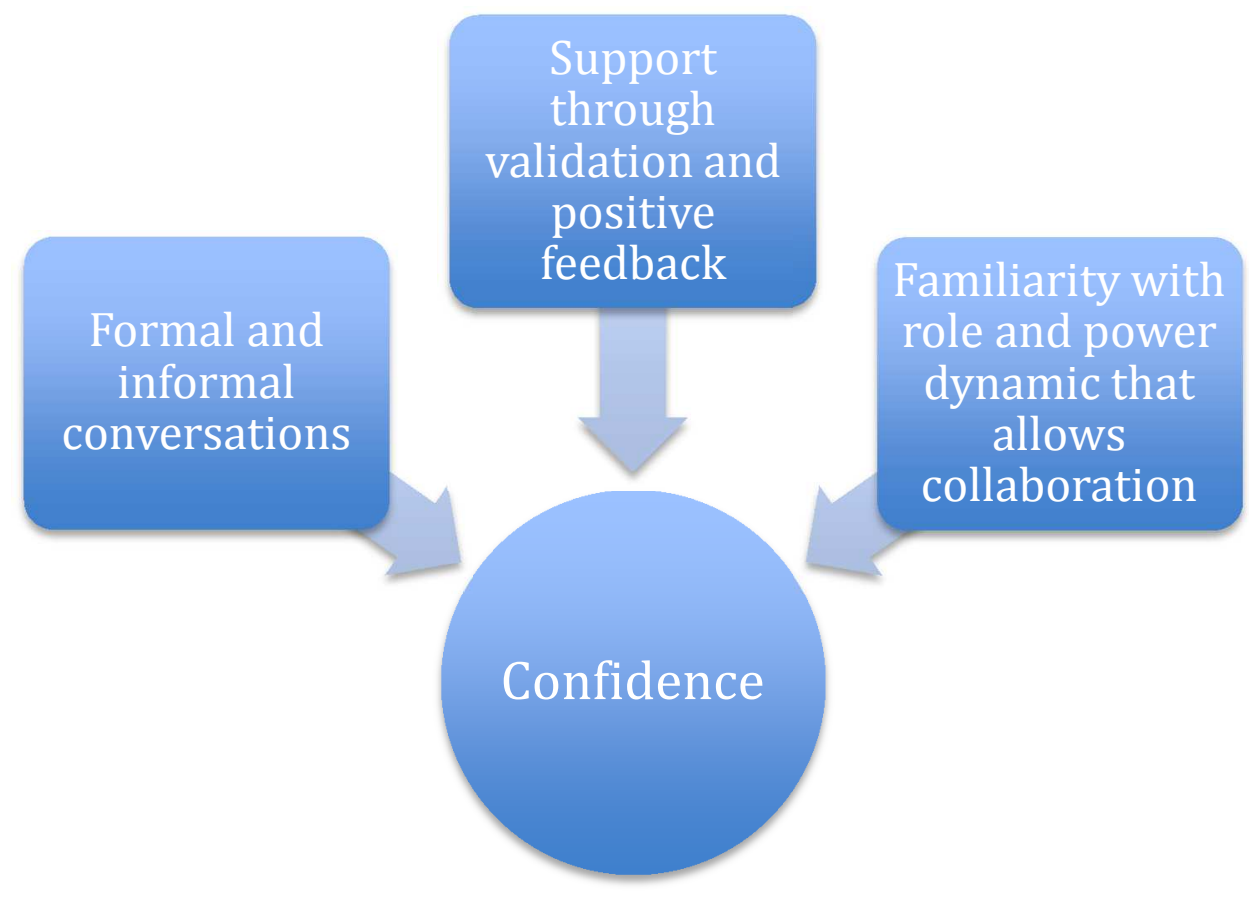

Figure 1.

The three themes that emerged from my data and their contribution to parent confidence in their role are illustrated in the diagram above. Familiarity with role and power feeds into confidence and is increased by frequency of formal and informal communications - supported through validation and positive feedback. Confidence is not the same thing as cultural capital - it is seen as one aspect that can lead to activation of cultural capital. In Patricia's case she was confident in her role as parent, but she was not confident in her role within the parent-teacher conversation. She lacked frequency of formal and informal conversations, she did not feel supported in her role or receive any positive feedback and she felt disempowered in her interactions. She lacked confidence in 
her role and her cultural capital was not activated. On the other hand, Linda had frequent conversations with teachers, she experienced both negative and positive interactions and learned from them and she grew into her role and gained confidence and trust. Ultimately Linda felt confident that she could get what she wanted from teachers within their interaction - her cultural capital was activated. Both Patricia and Linda are middle-class mothers, but their experiences are starkly different.

In this chapter I have described the demographics of the parents I interviewed and what categories they fell into based on Lareau's definitions of social class. I have described how the parents answered my research questions and how their answers show that they might use the parent-teacher relationship as a way to activate cultural capital through confidence in their role and collaboration with teachers. I have talked about how formal and informal conversations can strengthen that confidence and collaboration and how barriers and supports can help or hinder that collaboration. Finally I have described the role of primary parent and discussed how parents who perform this role have access to the benefits that might help them activate their cultural capital. 


\section{Chapter 5: Discussion}

In this chapter I will go over the themes from my results section within the context of the relevant literature. First, I will show how confidence as a concept has been used in the literature as a marker for cultural capital in order to justify my use of confidence in role as an indicator of the activation of cultural capital. Next, I will address each of the themes and how they show up in the literature and how they contribute to the confidence expressed by the parents I interviewed. Further, I will explore the concept of primary parent as it is defined in the literature, how well the narratives of the parents I interviewed fit within that definition, and how that plays in to who has access to the parent-teacher relationship as a mechanism for activating cultural capital. I will end with a discussion of how my results contribute to the existing literature on parent-teacher relationships.

\section{Confidence}

In this section I will look at how the existing literature has used confidence as a measure of cultural capital when looking at the parent-teacher relationship. First I will talk about the literature that describes the cultural and social capital held by middle-class parents as a barrier to working-class parent involvement. In addition, I will discuss the different ways that middle-class parents harness the capital available to them, whether cultural or social. Within this discussion I will describe how my results reflect a different view of the barriers to involvement and conversation with teachers. Finally I will show 
how the parents I interviewed felt more confident in their role in conversations with teachers, regardless of class background, as a result of engagement over time.

In her book Unequal Childhoods Annette Lareau talks about the barriers working class and poor parents encounter when dealing with educational institutions. Lareau explains that while "while working class and poor parents are no less eager than middleclass parents to see there children succeed in school," they go about the process in different ways (Lareau 2011, 198). Rather than being assertive in pursuit of their goals for their children, Lareau claims that working class and poor parents "typically are deferential rather than demanding toward school personnel (Lareau 2011, 198).

Lareau describes a dichotomous structure in which parents with low SES backgrounds are marginalized and feel frustrated by the lack of support within the institution (Lareau 2002, 773). Other research supports her findings and suggests that parents with middle and upper income feel entitled and free to access resources within the school system through which their children matriculate (Horvat et al. 2003, PoseyMaddox 2013, Reay 1999). On the other hand, some of the research Lareau conducted earlier argues that the real question is whether or not cultural capital is activated, which might not be dependent on social class (Lareau and Horvat 1999). Freeman argues that working-class parents can access cultural capital through the discursive positioning they do in their conversations with teachers (Freeman 2010). The discursive positioning described by Freeman seems to demonstrate the activation of cultural capital described by Lareau. However, there are still advantages ascribed to middle-class parents in both cases (Lareau and Horvat 1999, Freeman 2010). 
In my research I found that almost all the parents I interviewed, regardless of social class, felt confident in their role within the parent-teacher relationship. They were not only confident in their role, they were able to collaborate and work in partnership with teachers in order to further the interests they had for their children. With one exception the parents felt that the conversations they had with teachers over the years helped increase their confidence in their roles. In fact, one mother who had grown up in a low-income environment and who herself had been on public assistance recently seemed to navigate the structure of her daughter's elementary school with practiced ease. Her $5^{\text {th }}$ grader was the second child she had been through the process with and she mentioned learning much from her experiences with her older daughter and from dealing with teachers.

On the other hand, a mother I interviewed who was well established in the middle-upper income bracket was the only parent I spoke with who felt alienated from the teachers and marginalized from her son's experience. She cited the barrier of time and workload as reasons for the inability to collaborate with her son's teachers.

I feel like they have got their plan of what they are going to say and I feel like they just need to get through 25 kids... I don't know... it's really hard to get to them because I work and it's hard to make an appointment that we can both meet... they are usually gone right after school (Mom, 42).

In a previous article, Lareau detailed the differences between parents in a working-class and low-income neighborhood, versus parents in a middle-upper income neighborhood. She described the parents in working-class neighborhoods as "reluctant to contact the school... uncomfortable in their interactions in the school" (Lareau 1987, 78). 
On the other hand middle-income parents were described as frequently contacting teachers to "discuss their child's academic progress" (Lareau 1987, 78). In contrast, all the parents I interviewed except one voiced the opinion that teachers were available to them, particularly via email. Feeling confident that teachers are available to them suggests that parents feel confident in their ability to activate their cultural capital. Parents do not voice reluctance to contact school, instead they feel only limited by time and see email as a method of reaching out beyond the time constraints they see as barriers.

The literature on parent involvement based in America evaluates cultural capital in a fixed way - Middle-class parents have it, while working-class and low-income parents feel marginalized or frustrated because the cultural and social capital that they possess is not valued (Lareau 2002). My study suggests that cultural capital is not necessarily a fixed resource, that it can be developed in dialogue with a person who holds institutional capital - in this case conversations with teachers. Like the intentional discursive positioning described by Freeman (2010) and the activation of cultural capital described by Lareau (1999), the parents in my study showed activation of capital through the confidence they felt in their role and collaboration with teachers they described.

\section{Formal vs. informal}

Part of what helps parents gain confidence in their role is the amount of conversation with teachers. While previous research suggested that working-class and low-income parents might feel reluctant to contact teachers (Lareau 2002, Horvat, 
Weininger and Lareau 2003, Freeman 2010), nine out of the ten parents in my study expressed confidence in their ability to contact teachers and identified email as a way to connect when schedules conflicted. The number of conversations that parents have with teachers increases over time, but over shorter periods of time the number of conversations can also increase due to frequency of interaction. My study shows that formal and informal means of communication were both utilized by parents in order to develop an ongoing dialogue with their children's teachers. In this section I will first look at how both formal and informal conversations between parents and teachers are viewed in the literature. I will then point to specific methods of communication discussed by the parents I interviewed and how those conversations influenced the level of confidence parents felt in their role within the parent-teacher conversations. Additionally, I will discuss how the confidence parents gained through these micro-interactions helped them activate their cultural capital. In activating their cultural capital parents increased their ability to work collaboratively with teachers

The primary formal conversation between parents and teachers is the parentteacher conference. Sarah Lightfoot-Lawrence focuses exclusively on the formal conversation contained in the parent-teacher conference primarily from the teacher perspective (Lawrence-Lightfoot 2003, xxvi). Lawrence-Lightfoot describes the conversation as being informed by the past experiences of both parents and teachers. In other words, the way parents and teachers viewed their own parents going to conferences effects the way they feel about their role in the conversation. Further, Lawrence-Lightfoot describes the conference as the "Essential Conversation" because it shapes the development of children as they move through school. 
In my study, parents did not refer to their experiences with conferences their parents had when they were children or their perception of how their parents handled things, other than to say that they felt like there were more conferences when they were in elementary school. Nine of the parents said that they wished there were more conferences, although one of them said he didn't want to take time from instruction days in order to have one. The interest parents had in additional conferences reflects how much they value their conversations with teachers and how important they feel the connection is to their children succeeding. There were no differences in this perspective based on the social class of the parents I interviewed.

In terms of parent participation, perhaps the dichotomy between parent experiences is more focused on larger participation in which parents come into communication with other parents from different class backgrounds. However, this would be reflective of social capital and only applicable when it comes to membership in a social group of other parents. The one-on-one communication between parents and teachers offers a chance for a micro-interaction where parents can gain confidence in their role and activate cultural capital, which increases their ability to understand and ask for resources that might be available to them. This one-on-one interaction seems to facilitate activation of cultural capital rather than social capital. Still, the level of social capital is influenced - since the effectiveness of a parent networks social capital is contingent on the individual cultural capital of each member in the group.

Parents are now solicited constantly to participate in their children's school and education, particularly in elementary school. However, "Many forms of parental 
involvement are often not recognized as participation by schools" (Anderson 1998, 589). Anderson lists many activities including "talking by phone with the teacher" as neglected forms of parent participation (Anderson 1998, 589). This lack of recognition may be part of what some of the literature describes as a preference for particular forms of participation from parents. Previous literature suggests that teachers prefer the methods of assertive communication employed by middle-class parents (Lareau 1987).

In my study it was clear that nine of the parents felt very comfortable with their ability to engage in conversations and although they were troubled by the lack of additional conferences, they mentioned email as a form of continuing the conversation and keeping up a cohesive relationship. The prevalence and possibilities contained in email was something that emerged unexpectedly from my interviews with parents. The parents I interviewed talked about the importance of informal conversations and also the importance of email. While email is touched upon in some of the literature as an avenue of communication, I believe that its significance is not adequately understood. One of the parents mentioned the prominence of email and how helpful it is when he said:

I also have to respect the teacher's time. I can't go in and ask for 15 minutes of her time every time I have a question. It's easier to just shoot them off an email. And they're so good about it. Universally, I get an email that same day, unless it's late at night and then it will be first thing in the morning (James, 40).

In describing his email communication this father reveals the convenience of the communication in that he can "shoot off an email" at any time without worrying that he is "bothering" the teacher because he knows that the teacher will get to the email when they 
can. In his description of email, James is giving evidence of activation of cultural capital as described by Lareau and Horvat (1999).

Another example of the way that email can be beneficial was given by Linda when she said "its easier for me to be able to sit and think exactly what I am trying to communicate and what I want to say “(Linda, 36). In her statement, Linda is recognizing that in addition to email being convenient, it also allows her to be more thoughtful in how she forms her questions and responses, so that they can be more effective. Linda also spoke about collaboration with her son's teacher and described a shift in the effectiveness of her communication that can again be connected to Lareau's concept of activation of cultural capital.

Both James and Linda were in the middle-class parent bracket, but both of them talked about a learning curve in developing confidence in their role. I thought this was interesting because based on the literature, I expected middle-class parents to feel confident in their role from the beginning. Instead all of the parents I interviewed described a discomfort or lack of familiarity and uncertainty about how to proceed when their children entered school. On the other hand, all of the working-class and low-income parents I interviewed expressed that they eventually gained confidence in their ability to deal effectively with their children's teachers.

Often the literature seems to treat the parent-teacher communication as parents meeting emissaries from an institution. The Essential Conversation by Sara LawrenceLightfoot describes how important the parent-teacher conversation is and the consequences of not acknowledging how important it can be. Perhaps focusing on that 
relationship and the potential benefits of all the communication would be more helpful than focusing on the larger means of parent participation. In an era where parents have become instrumental in the elementary school years, it is crucial to understand how to make collaboration between parents and teachers more fruitful. In fact, "a growing number of researchers stress the importance of rethinking the traditional parental involvement" (Tveit 2009, 289).

The literature around parent participation in school references both cultural and social capital. As mentioned earlier in the literature review, it is important to understand the difference between these two forms of capital, but also how they are related. It is worth spending some time talking about each of these concepts and how they contribute to our understanding and support of parent involvement in elementary school. Diane Reay talks about the importance of cultural capital in "relation to the growing emphasis on parental involvement and parental choice" (Reay 2004, 73). Choice is a motivating factor in parents assuming the role of instigator in parent-teacher conversations.

Reay interprets Bourdieu's "concern in relation to cultural capital" with the "continual transmission and accumulation in ways that perpetuate social inequalities" (Reay 2004, 74). The literature reflects this transmission in the broader conversation of parent involvement, but on a micro level the interaction between parents and teachers in my study reveal something different. Within their communications with teachers, it seems that parents can have an avenue of access and influence that to some extent transcends social class - at least to some degree. With their increased confidence in their role, parents I interviewed felt better able to help their children succeed academically. In 
addition, parents felt more confident in their partnerships with teachers - where they would work together to help their children succeed emotionally and socially as well.

Reay argues "levels of confidence and entitlement are key dimensions of cultural capital across social fields" (Reay 2004, 75). She agrees with earlier assessments by Lareau and Weininger that "micro-interactional processes whereby individuals' strategic knowledge, skills and competence comes into contact with institutionalized standards of evaluation" must contribute to our understanding of how cultural capital is acquired (Reay 2004, 75). Part of the confidence gained by parents includes feeling validated in their role by teachers. - a sort of "institutionalized standard of evaluation" as described by Reay (2004). In this way I believe that the confidence parents expressed in my interviews with them demonstrates activation of cultural capital. Because of this I argue that the results of my research suggest parent-teacher communication is one avenue by which parents gain the "confidence and entitlement" through activating their cultural capital and thus this relationship deserves more attention in both policy and research.

Since activating the cultural capital of individual parents will increase the resources any parent in their network can utilize, social capital may also be increased through parent-teacher relationships. Social capital is described more fully in an article by Horvat, Weininger and Lareau detailing the use of parent networks as an avenue for accessing social capital (2003). Horvat et al. argue that "social capital may be just as likely to function as a mechanism that facilitates the intergenerational transmission of advantage as one that ameliorates its effects" (Horvat et al. 2003, 321). They build on the 
notion of social capital provided by Coleman $(1988,1990)$ particularly citing "examples of intergenerational closure and parent-child relations" (Horvat et al 2003, 321).

Further, Seaman and Sweeting suggest that "social capital resides within the relations between individuals and is the means by which they access and harness other forms of capital" (Seaman and Sweeting 2006, 175). I argue that this describes some of what happens in the parent-teacher conversations - the cultural capital activated by parents is brought about by the dialogue that transpires over time and the confidence they develop in their role as parent. Subsequently, that capital has the potential to be shared with other parents through the parent social networks that have already been documented. This is an area for further exploration. While much time has been spent looking at the larger social groups surrounding elementary education, some research has argues for attention to be paid to the "importance of the quality and nature of relationships and not the mere number of them" (Seaman and Sweeting 2006, 177). I suggest that the parentteacher relationship is an example of exactly the kind of relationship that needs to be examined further.

In this section I have discussed the ways that formal and informal conversations have been described in the existing literature. I have talked about how the parents I interviewed detailed various modes of communication and what they found most helpful. Overall I have shown how the frequency of communication can help parents feel more comfortable in their role and help them navigate the parent-teacher relationship and the conversations that surround their interactions with teachers. As parents get more 
confident in their role, they shift between the available options and the power dynamic also shifts.

\section{Role and Power}

In this section I will discuss the different roles for parents within the parentteacher relationship as described in the existing literature. Some of the roles described in the literature are advocate, listener, instigator, partner, collaborator and the role of teacher as obstacle or partner (Lareau 2002, Freeman 2010, Yoder \& Lopez 2013, Gillies 2006). Mostly these roles are described from the perspective of the teacher, institutional administrators and researchers. My study adds to our understanding about how parents perceive their role by addressing them directly in semi-structured interviews and asking them to reflect on how they perceive and how they feel about their role. Parent's perception of their role relates to cultural capital in that different roles might find activation of cultural capital easier or more likely. For example, if parents view their role as collaborator, it is likely they are able to activate their cultural capital. In contrast, if parents view the teacher role as an obstacle, it is likely that they are not able to activate their cultural capital.

Lareau describes the role of passive listener on the part of the parent when she mentions that "in the working-class community, parents turned over the responsibility for education to the teacher" (Lareau 1987, 81). However, when she describes the role of middle-class parents she reveals that those parents "saw education as a shared enterprise and scrutinized, monitored, and supplemented the school experience of their children" 
(Lareau 1987, 81). Posey-Maddox finds that not only is there a divide between the power held by middle-class parents and low-income parents, the engagement of middle class parents may "ultimately create new patterns of inequality in local school districts contexts" (Posey-Maddox 2012, 237). Both Lareau and Posey Maddox seem to contribute to the idea that middle-class parents inhabit the role of instigator while working-class and low-income parents take on a more passive role - chiefly that of listener.

Freeman talks working-class parents taking on the role of advocate. She describes this process as a battle for the parents, one that comes from "the awareness they have built from experience about the need to fight against discriminatory practices" (Freeman $2010,191)$. She argues that the "implementation of real conversations around concrete situations has the potential to encourage a co-constructed involvement that would be more inclusive of all parents" (Freeman 2010, 195). My study shows that she is right and that at least some of the time the conversations between parents and teachers can act as a resource for parents from all backgrounds, including low-income parents. However, none of the parents in my study described a "need to fight against discriminatory practices" Freeman described (2010). Working-class parents in my study instead described teachers as very receptive to their input.

There is some evidence that schools can help determine the success and contribution of the parent-teacher relationship. Some researchers have argued that the "parental role is dually formed; parents perceive of the role as a function of how the school treats them" (Tveit 2009, 295). Tveit frames her analysis as a "hypothesis-creating 
study offering clear directions for further research" (Tveit 2009, 297). She draws her data from texts written by the NPC, a "national committee for parents who have children in primary and secondary school" (Tveit 2009, 291). Her study "reveals that the NPC provides conflicting signals regarding the roles of parents and teachers" (Tveit 2009, 298). Part of my motivation for this study was to get a better understanding of how parents view their own role in the parent-teacher conversation.

In the study by Tveit, the effect of social class is not discussed because the texts only imply diversity of parent backgrounds (Tveit 2009, 295). She notes that the lack of explicit discussion of class might "obscure the fact that the school seems to support the culture of some families, while systematically excluding others" (Tveit 2009, 295). In saying this Tveit seems to be maintaining the stance that working-class and low-income families might perceive their role differently than parents from middle-class backgrounds. In my interviews I found that all the parents I talked to viewed their role in a similar way. Two of the parents I interviewed were from low-income backgrounds, five of the parents were from middle-class families and three of the parents were from working-class families. Nine of the ten parents I interviewed said they had more confidence in their role as parent as a result of conversations with teachers.

Parents from all backgrounds spoke of asking questions and getting on the same page with teachers. While nine of the parents I interviewed spoke of confidence and collaboration in a way that signaled activation of cultural capital, one parent showed confidence in her role as parent, but did not show activation of her capital in that her dealings with teachers left her frustrated. Patricia describes this frustration in an 
encounter she had with a teacher over the way the teacher spoke to her son and she ends by saying "nothing ever happened, nothing changed. She still yells at the kids. There's no support. I don't know... it's I don't.... I'm still so angry about it”' (Patricia, 42). Patricia is a middle-class mother and yet she is unable to activate her cultural capital and get a satisfactory response from her son's teacher.

Parents I interviewed spoke of assuming the role of listener or instigator regardless of class background. In addition, several of the parents spoke about moving between roles. It could be that this is a function of the culture of parent involvement that has increased in the time since Lareau first began her research, or perhaps it is a regional variation. However, it seems likely that to the extent that a school district might be similar to the Portland Metro Area, the experiences within that district might be similar as well.

There is growing emphasis on the importance of parent-teacher conversations in the relevant literature. One study provided training for schools "which emphasized the building of parental engagement and confidence with up to three structured conversations a year" (Day 2013, 37). In fact, two of the parents I interviewed had Individual Education Plans (IEPs) for their children and those explicitly mandated three conferences for them each year, although all of the parents I interviewed reported that there was only one formal conference scheduled per year as a rule. In both cases when I asked the parents how they got the IEPs, the parents responded that they were physician directed. Nine of the ten parents I interviewed saw the low number of conferences as a barrier to comfort and confidence in their conversations with teachers. 


\section{Barriers and Supports}

In this section I will talk about the different barriers and supports for parents as described by the literature and as defined by the parents I interviewed. I will discuss how the information I gathered in the interviews relates to the literature on barriers and supports. Finally I will suggest that while there may be barriers in terms of a parent feeling confident with his or her role in the parent-teacher conversation, the relationship between parents and teachers is still an opportunity for activating the cultural capital of parents with respect to education and that this opportunity is available not just to middleclass parents, but to working-class and low-income parents as well.

One of the most prominent barriers the literature describes for working-class and low-income parents is the entitlement of middle-class parents. Reliance on the participation and contributions of the middle-class parents has been seen to engender tensions and exacerbate "existing status positions among parents" (Posey-Maddox 2012, 235). Posey-Maddox further asserts that "research has shown middle-class parental involvement to reinscribe, rather than counter, class-based inequities in public schooling through support of policies such as tracking that favor these parents' children at the expense of others" (Posey-Maddox 2012, 236).

It turns out that the most prominent barrier parents mentioned was the lack of time teachers have. The parents spoke of teachers as overworked, and strapped for resources. One parent described the difficult position that teachers have when he said:

I think they are un-thanked, underpaid, underappreciated. It's really a thankless job so you have to be really a self-motivated person. Certainly you know a teacher calls the students her kids, so there is a really 
emotional role there as well. So, they are obviously getting social benefits out of it, but not the type of respect I think that they might deserve from society at large (James, 40).

Some of the barriers and supports mentioned in the literature lead into the discussion of roles that parents might take on. For example, parents who feel marginalized and frustrated might be inclined to take a less assertive role and do more listening within conversations with teachers. Parents who feel entitled and confident in their right to ask for theirs or their children's needs to be met, might act as instigators in the conversations they have with teachers. The literature up until now seems to bear this out.

\section{Primary Parent.}

Primary parent as used in this study refers to the parent most involved in conversations with their children's teachers. It can be situated in the literature within the concept of "primary caregiver" - a role traditionally held by mothers. In fact, the literature also describes the elementary school teacher role as one conventionally held by women as well. In her book on the formal conversation that occurs in parent-teacher conferences, Lawrence-Lightfoot implies that the fact that this conversation largely occurs between women might be a factor in how it is minimized and undervalued in our culture (Lawrence-Lightfoot 2003, xxvi).

The role of mother as primary caregiver extends to encompass the role of primary communicator with schools. "The roles of women are heavily overlaid with domestic and 
status production for the family, with concern for children and schooling being the domain of women" (Landeros 2011, 247). On the other hand, this gendered way of looking at the parent-teacher relationship might be less explicit within our culture since "much of the writing on parental involvement often works on the implicit assumption that all parents share an identical experience of involvement” (Reay 1999, 159). Reay maintains that the emphasis on identical experience hides the fact that women have a “largely unshared responsibility for their children's schooling” (Reay 1999, 159).

Among the parents I interviewed the role of primary parents was held mostly by the women, although one father explained that he took on the role of primary parent and a second father said he would like to be more involved. In this way my results confirmed what is described in the literature when it comes to who holds the role of primary parent. In both the literature and my results mothers, with one notable exception, held the primary role predominantly. If the parent-teacher relationship is a place where parents develop cultural capital, the primary parent is the one who gains that resource.

One parent in particular expressed appreciation for the extra familiarity she has from being the primary parent in the parent-teacher relationship. "I feel very fortunate to be as involved as I am in my child's school day. Just being able to be the one that $99 \%$ of the time picks her up from school and drops her off at school. I feel very fortunate for that" (Maria, 50). Maria elaborates that her position of primary parent gives her a better sense of what is going on at school when she says that she gets to:

see the atmosphere of the school and the environment from entering when the bell rings to getting settled into the classroom and what the atmosphere is as the days getting started, whether there is a substitute teacher or... I 
definitely have a good sense of what the kid's schedule is for the day... if it's PE day or band day or what's on the lunch schedule. (Maria, 50)

In this section I have shown how the concept of primary parent can be housed within the concept of primary caregiver. I have talked about how the social construction of gender and mothering roles have made it more likely that the role of primary parent is held by mothers, but I also shown an example of that role being performed by a father and suggested an avenue of further inquiry regarding the role of gender in how the parent-teacher relationship might be viewed going forward. Finally I talked about the information I gathered and how it fits within the literature. A key understanding is that the primary parent is more familiar with the school and with the teacher and this gives them more confidence in their role within conversations. This might be an important concept to carry forward in future research, particularly research that looks at gender difference in parent-teacher relationships.

\section{Research Strengths}

This research addresses a gap in the literature about opportunities for low-income parents to utilize conversations with teachers in elementary school as a means of activating cultural capital. This study builds on work done by Melissa Freeman who identified working-class parents using "discursive positioning" to activate cultural capital in their dialogue with primary school teachers in England. Most of the research thus far has been more micro level and focused on the marginalization of lower SES parents and the entitlement of higher SES parents. 
There is a growing body of literature on the more micro-level interactions between parents and teachers, but this focus is relatively under-researched. This is important because while parents might feel restricted and unable to approach schools on an institutional level, almost all parents have access of some kind to their children's teachers through parent-teacher conferences and other less formal ways of communicating. If the relationship between parents and teachers can indeed help parents gain the tools they need, then policies and practices that facilitate better communication pathways should be explored.

This study also addresses a group that can be seen as typical for the Portland Metro Area. The children of the parents I interviewed go to schools that are predominantly white, with parents in a variety of income levels and from different class backgrounds. To the extent that these things were found in other school districts, I would expect to see similar results. Because of this, one of the strengths of this research is that it is likely to be transferable in similar contexts.

\section{Research Limitations}

All research is subject to limitations and understanding those limitations helps both validate the strengths of the research as well as place it into context when looking at other similar research. One of the limitations of qualitative research is that small studies produce a large quantity of data about relatively few individuals. Because of this the sample size of qualitative research is restricted in ways that other research is not. Thus, broad generalizations about class are not possible based solely on this study. For this 
reason it is important to be mindful of what previous literature has suggested and stay close to the guiding theory.

It is also important to consider researcher bias when thinking about limitations not only with the analysis of data that is collected, but on the questions asked and even the interest to do research in the first place. Many of us study what we know and what is familiar to us and because qualitative research looks at perceptions and understanding rather than numbers and frequencies, it becomes even more critical that we check our biases because too easily we can write our own story onto what others say, particularly if we agree with them.

I come at this research from the perspective of being a parent and with one of my children enrolled in $5^{\text {th }}$ grade. This both motivates me and at the same time reminds me that I have to check my bias often. In order to mitigate the limitations within this context as much as possible, I gave my participants the opportunity to check the transcripts and make sure that I was accurately reporting what they had said, I also asked clarifying questions and invited them to check in with me at any time if they had questions or concerns.

An additional limitation is the lack of diversity in my participants when it comes to race and ethnicity or cultural differences. Parents who experience marginalization because of language barriers or institutionalized racism would be likely to have very different experiences from the parents I interviewed. However, I believe that the information I found in my research could be a starting point for asking similar questions in different populations and that parallels could be drawn. Further, while previous 
research has found that race was important in how parents interacted with schools (Lareau and Horvat 1999), Lareau later found that it is more class than race that makes parents feel marginalized (Lareau 2002, 773). Because Lareau found that race mattered more in an earlier study while class mattered more in a later study, it may be that region and historical time have an effect on which factor matters most. 


\section{Chapter 6: Conclusion}

A cohesive parent-teacher relationship is critical for addressing problems that come up for kids in the most effective manner. Informal and positive communication strengthens trust and adds to cohesion. Validation of roles and reasonable distribution of power within the relationship also adds to the success of the communication parents have with teachers. Experience with the institution through informal conversations might play as much if not more of a role in parent confidence than sociological categories of stratification - further study is needed to be able to make this claim.

The themes of formal and informal conversations, role and power, barriers and supports all tie into the complicated dynamics surrounding the parent-teacher relationship. It might seem obvious, but the same things that help build trust in all intimate relationships are also important in the parent-teacher relationship. Parents trust teachers more when teachers seem involved, when they reach out, when there are frequent communications both formal and informal and both positive and negative. Parents want to know that teachers are available and yet they are also conscious of the time constraints teachers face. Perhaps because of the parent's awareness of how overwhelmed teachers are, small signs of involvement on the part of the teacher make a big impact on parents. A brief positive email, a follow up to a previous conversation these moments help parents feel validation and connection and build trust. Trust is an important component in building collaborative relationships and activating cultural capital (Lareau and Horvat 1999). 
I view the parent-teacher relationship as a meeting between two experts in different fields. The teacher is the expert in the classroom and curriculum and the dynamics of the school day. The parent is the expert in their particular child and their personality, how they engage emotionally and socially outside of school, things that their child struggles with. Because academic achievement involves attention to academic, social and emotional development, both types of expertise are needed. Parents and teachers depend on each other and children depend on a strong partnership so that they can have the best possible chances.

It seems as though the more informal conversations parents have with teachers, the more confidence they feel in their role, and the more they feel like collaboration is going on. More collaboration contributes to shared understanding of goals and partnership in helping children succeed academically, socially and emotionally. Some of the parents may not have the ability to engage in a lot of formal conversations and certainly this gets harder if one is a single parent. However, the growing prevalence of email allows busy parents to communicate more frequently with teachers who are also busy. Because email creates the possibility for so much opportunity in the parent-teacher relationship, further study is warranted. Teachers should also be interviewed about their perspective and experience regarding email.

Several parents discussed the importance of informal conversations and the only parent with negative things to say is the only parent who lacked ongoing informal conversations with her child's teachers. I interviewed her early on in the process and now if I were to encounter a parent with that perspective, I would ask them about the barriers 
to forming relationship through informal conversations. I would ask about the conversations they have with teachers outside of the structured formal conversations. There are probably multiple barriers that keep parents from engaging and some might be tied to race or class or language, another possibility is lack of time.

The most important finding of my study is that cultural capital need not be seen as a fixed resource in reference to parents. Freeman's research found that working-class parents were able to activate cultural capital through dialogue with their children's teachers. In my research I found that low-income parents were also able to activate cultural capital through the parent-teacher relationship - with time and experience in both formal and informal conversations.

Freeman argues that parents are intentional in their positioning and quite deliberate in their moves to gain capital in dialogue. In line with this reasoning, some of the parents I interviewed spoke of "instigating conversations" and some frustration when they needed to be the ones to call attention to issues. However, I felt that most of the parents spoke of the confidence they gained in dialogue as a natural process. They described teachers as receptive to their questions and participation, regardless of class background.

My study directly addresses a gap in the literature on whether or not the cultural capital of working-class and low-income parents can be activated. I show that, in addition to working-class parents, low-income parents can activate cultural capital through conversations with their children's elementary school teachers. In doing so they increase their ability to act on behalf of their children toward positive academic outcomes. It is 
important to encourage further research in this area because it presents an opportunity to increase equity in different school systems through empowering parents in their role.

I hope to continue this research for my dissertation and I would like to look more closely at how informal conversations are perceived by both parents and teachers. I would also like to look at how email has increased the opportunity for frequent conversations and how that plays into parent confidence in their role. I want to explore how teachers view email. Because I used a convenience sample which included known contacts and snowball methods for recruitment, I knew that the participants would come from a variety of backgrounds and that the class background in the schools their children attended were correspondingly diverse. In future research I would like to talk to parents and teachers from a school servicing a high number of low-income and working class families so I can look more specifically at the effect of informal conversations and email on a broader scale. 


\section{References}

Bourdieu, Pierre and Jean-Claude Passeron. 1990. Reproduction in Education, Society and Culture. Sage Publications: London.

Bourdieu, Pierre. 2011. "The Forms of Capital. (1986)." Cultural Theory: An Anthology. 81-93.

Charmaz, Kathy. 2006. Constructing Grounded Theory. Sage: London.

Coleman, James S. 1988. "Social Capital in the Creation of Human Capital." American Journal of Sociology. 94(Supplemental): S95-S120.

Day, Sara. 2013. "Terms of Engagement" not "Hard to Reach Parents." Educational Psychology in Practice: Theory, research and practice in educational psychology. 29(1): 36-53.

Freeman, Melissa. 2010. "Knowledge is acting: Working-Class Parents Intentional Acts of Positioning within the Discursive Practice of Involvement." International Journal of Qualitative Studies in Education 23(2): 181-198.

Geleta, Esayas B. 2014. "Social Capital as Collateral: Banking on the Poor." American Journal of Economics and Sociology 73(1): 108-125.

Gillies, Val. 2006. "Working Class Mothers and School Life: Exploring the Role of Emotional Capital. Gender and Education 18(3): 281-293.

Harre, Rom. 1991. “The Discursive Production of Selves.” Theory Psychology 1(1): 5163.

Harris, Alma and Janet Goodall. 2008. "Do Parents Know They Matter? Engaging All Parents in Learning." Educational Research 50(3): 277-289.

Henderson, Morag. 2013. "A test of Parenting Strategies.” Sociology 47(3): 542-559.

Horvat, Erin M., Elliot B. Weininger and Annette Lareau. 2003. "From Social Ties to Social Capital: Class Differences in the Relations Between Schools and Parent Networks." American Educational Research Journal 40(2): 319-351.

Horvat, Erin M. and Annette Lareau. 1999. "Moments of Social Inclusion and Exclusion Race, Class, and Cultural Capital in Family-School Relationships." Sociology of Education. 72(January): 37-53.

Landeros, Mary. 2011. 'Defining the 'Good Mother' and the 'Professional Teacher': Parent-Teacher Relationships in an Affluent School District." Gender and Education 23(3): 247-262.

Lareau, Annette. 1987. "Social Class Differences in Family-School Relationships: The Importance of Cultural Capital." Sociology of Education 60(April): 73-85.

Lareau, Annette. 2002. "Invisible Inequality: Social Class and Childrearing in Black Families and White Families.” American Sociological Review 67(5): 747-776. 
Lareau, Annette. 2011. Unequal Childhoods. University of California Press: Berkeley and Los Angeles, California.

Lawrence-Lightfoot, Sara. 2003. The Essential Conversation. Ballantine Books: New York, New York.

Lee, Jung-Sook and Natasha K. Bowen. 2006. "Parent Involvement, Cultural Capital, and the Achievement Gap Among Elementary School Children." American Educational Research Journal 43(2): 193-218.

Marshall, Catherine and Gretchen B. Rossman. 2011. Designing Qualitative Research. Sage: Los Angeles, CA.

Mitescu, Mihaela. 2014. "How do beginning teachers employ discursive resources in learning and affirming their professional identity?" Social and Behavioral Sciences 128: 29-35.

Oseguera, Leticia and Gilberto Q. Conchas and Eduardo Mosqueda. 2011. "Beyond Family and Ethnic Culture: Understanding the Preconditions for the Potential Realization of Social Capital.” Youth Society 43(3): 1136-1166.

Social Capital in School Performance of Immigrant Asian and Hispanic Adolescents." Social Science Quarterly 86(4): 928-949.

Posey-Maddox. 2013. "Professionalizing the PTO: Race, Class and Shifting Norms of Parental Engagement in a Public City School." American Journal of Education 119 (February): 235-260.

Reay, Diane. 1999. "Linguistic Capital and Home-School Relationships: Mothers' Interactions with their Children's Primary School Teachers." Acta Sociologica 42(2): 159-168.

Reay, Diane. 2004. "Education and Cultural Capital: the Implications of Changing Trends in Education Policies." Cultural Trends 13(2): 73-86.

Seaman, Peter and Helen Sweeting. 2006. "Assisting Young People's Access to Social Capital in Contemporary Families: a Qualitative Study." Journal of Youth Studies 7(2): 173-190).

Taylor, Lorraine C., Ivoran D. Hinton and Melvin N. Wilson. 1995. "Parental Influences on Academic Performance in African-American Students." Journal of Child and Family Studies 4(3): 293-302.

Todd, Elizabeth S. and Higgins, Steven. 1998. "Powerlessness in Professional and Parent Partnerships.” British Journal of Sociology of Education 19(2): 227-236.

Tveit, Anne Dorthe. 2009. "A Parental Voice: Parents as Equal and Dependent - Rhetoric about Parents, Teachers, and their Conversations." Educational Review 61(3): 289-300. 
Yoder, Jamie R. and Lopez, Amy. 2013. 'Parent's Perceptions of Involvement in Children's Education: Findings from a Qualitative Study of Public Housing Residents." Child and Adolescent Social Work Journal 30 (5): 415-433. 


\section{APPENDIX A: SURVEY INSTRUMENT}

\section{Interview Questions}

Tell me about your communication/conversations with the teachers your child has had in elementary school.

What kind of communications/conversations do you have?

How would you describe your role in the parent/teacher conversations?

How do you understand your role?

How do you feel about your role?

How would you describe the teacher's role in the conversations?

How do you understand their role?

How do you feel about their role?

What kind of conversations are the most helpful for you in supporting your role?

Is there anything you find challenging in the conversations you have had?

Has the way you talk with your children's teachers changed over the years?

If so, how?

Do you see your conversations changing as your child enters middle school?

Do you see your role changing? If so, how?

What kinds of communication with teachers do you find most helpful/meaningful?

How many conferences do you have a year?

Do you think the number of conferences is appropriate?

What do you expect from the parent-teacher relationship?

Thinking about what you know now and what your past experiences have been, do you have any hopes/goals about how to interact with your children's teachers in the future?

Tell me a story of one interaction that you have had with one of your children's teachers that stands out for you.

Why does that particular interaction stand out? 


\section{Short demographic survey}

Age?

Gender?

Marital status?

Education?

Occupation?

Annual Income (circle one)?

Less than $30 \mathrm{~K}$

$30-39 \mathrm{~K}$

$40-49 \mathrm{~K}$

$50-59 \mathrm{~K}$

$60+$

Number of children?

Birth order of $5^{\text {th }}$ grader? (oldest, middle, youngest, only) 